\title{
Actinide Arene-Metalates: Ion Pairing Effects on the Electronic Structure of Unsupported Uranium- Arene Sandwich Complexes
}

Jesse Murillo, ${ }^{\dagger}$ Rina Bhowmick, ${ }^{\dagger}$ Katie L. M. Harriman,, Alejandra Gomez-Torres, ${ }^{\dagger}$ Joshua Wright, ${ }^{\ddagger}$ Robert W. Meulenberg, ${ }^{ \pm}$Pere Miró, ${ }^{\star}$ Alejandro Metta-Magaña, ${ }^{\dagger}$ Muralee Murugesu, Bess Vlaisavljevich, ${ }^{*}{ }^{\star}$ and Skye Fortier*, ${ }^{\dagger}$

†Department of Chemistry and Biochemistry, University of Texas at El Paso, El Paso, Texas 79968, United States †Department of Chemistry, University of South Dakota, Vermillion, South Dakota 57069, United States

"Department of Chemistry and Biomolecular Sciences, University of Ottawa, Ottawa, Ontario K1N 6N5, Canada $¥$ Department of Physics, Illinois Institute of Technology, Chicago, IL, 60616, United States

${ }^{ \pm}$Department of Physics and Astronomy and Frontier Institute for Research in Sensor Technologies, University of Maine, Orono, ME, 04469, United States

\begin{abstract}
Chatt reaction methods were employed to synthesize the first well characterized actinide-arene sandwich complexes. Namely, addition of $\left[\mathrm{UI}_{2}(\mathrm{THF})_{3}(\mu-\mathrm{OMe})\right]_{2} \cdot \mathrm{THF}(\mathbf{2} \cdot \mathrm{THF})$ to THF solutions containing 6 equiv.

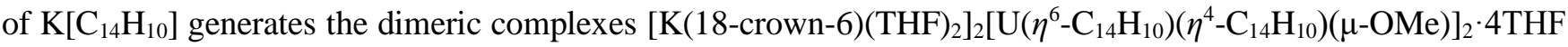
$\left(1^{18 \mathrm{C} 6} \cdot 4 \mathrm{THF}\right)$ and $\left\{\left[\mathrm{K}(\mathrm{THF})_{3}\right]\left[\mathrm{U}\left(\eta^{6}-\mathrm{C}_{14} \mathrm{H}_{10}\right)\left(\eta^{4}-\mathrm{C}_{14} \mathrm{H}_{10}\right)(\mu-\mathrm{OMe})\right]\right\}_{2}\left(\mathbf{1}^{\mathrm{THF}}\right)$ upon crystallization of the products in $\mathrm{THF}$ in the presence or absence of 18 -crown-6, respectively. Both $\mathbf{1}^{\mathbf{1 8 C 6}} \cdot 4 \mathrm{THF}$ and $\mathbf{1}^{\mathrm{THF}}$ are thermally stable in the solid-state at room temperature; however, after crystallization, they become insoluble in THF or DME solutions and instead gradually decompose upon standing. X-ray diffraction analysis reveals $\mathbf{1}^{\mathbf{1 8 C 6}} \cdot 4 \mathrm{THF}$ and $\mathbf{1}^{\mathrm{THF}}$ to be structurally similar, possessing uranium centers sandwiched between anthracene ligands of mixed tetrahapto and hexahapto ligation modes. Yet, the two complexes are distinguished by the close contact potassium-arene ion pairing that is seen in $\mathbf{1}^{\mathrm{THF}}$ but absent in $\mathbf{1}^{\mathbf{1 8 C 6}} \cdot$. THF, which is observed to have a significant effect on the electronic characteristics of the two complexes. Structural analysis, SQUID magnetometry data, XANES spectral characterization, and computational analyses are generally consistent with U(IV) formal assignments for the metal centers in both $\mathbf{1}^{18 \mathrm{C} 6}$. $4 \mathrm{THF}$ and $\mathbf{1}^{\mathrm{THF}}$, though noticeable differences are detected between the two species. For instance, the effective magnetic moment of $\mathbf{1}^{\mathrm{THF}}\left(3.74 \mu_{\mathrm{B}}\right)$ is significantly lower than that of $\mathbf{1}^{\mathbf{1 8 C} \mathbf{6}} \cdot 4 \mathrm{THF}\left(4.40 \mu_{\mathrm{B}}\right)$ at $300 \mathrm{~K}$. Furthermore, the XANES data shows the $\mathrm{U}_{\mathrm{III}}$-edge absorption energy for $\mathbf{1}^{\mathrm{THF}}$ to be $0.9 \mathrm{eV}$ higher than that of $\mathbf{1}^{\mathbf{1 8 C 6}} \cdot$ 4THF, suggestive of more oxidized metal centers in the former. Of note, CASSCF calculations on the model complex $\left\{\left[\mathrm{U}\left(\eta^{6}-\mathrm{C}_{14} \mathrm{H}_{10}\right)\left(\eta^{4}-\mathrm{C}_{14} \mathrm{H}_{10}\right)(\mu-\mathrm{OMe})\right]_{2}\right\}^{2-}\left(\mathbf{1}^{*}\right)$ shows highly polarized uranium-arene interactions defined by $\pi$-type bonds where the metal contributions are primarily comprised by the $6 d$-orbitals $(7.3 \pm 0.6 \%)$ with minor participation from the 5 -orbitals $(1.5 \pm 0.5 \%)$. These unique complexes provide new insights into actinide-arene bonding interactions and show the sensitivity of the electronic structures of the uranium atoms to coordination sphere effects.
\end{abstract}




\section{Introduction}

The structural elucidation of bis(benzene)chromium, $\mathrm{Cr}\left(\eta^{6}-\mathrm{C}_{6} \mathrm{H}_{6}\right)_{2}$, by E. O. Fischer was a landmark discovery as it established a new chemical bonding paradigm for both transition metal and carbon molecules alike, ${ }^{1}$ expanding upon the seminal structural characterization of ferrocene a few years earlier. ${ }^{2-3} \operatorname{In} \operatorname{Cr}\left(\eta^{6}-\mathrm{C}_{6} \mathrm{H}_{6}\right)_{2}$, the molecule features a formally chromium( 0 ) atom sandwiched between two neutral benzene rings wherein stabilization is bidirectional: donation of the benzene $\pi$-electrons into empty metal orbitals accompanied by backbonding of occupied metal orbitals into the empty benzene $\pi^{*}$-orbitals. ${ }^{4-5}$ This contrasts the bonding scheme in $\mathrm{Cp}_{2} \mathrm{Fe}\left(\mathrm{Cp}=\eta^{5}-\mathrm{C}_{5} \mathrm{H}_{5}\right)$, which is considered to contain an iron(II) center sandwiched between two $\pi$-donating, anionic, aromatic $\mathrm{Cp}^{-}$ligands with negligible backbonding character. ${ }^{6}$ Indeed, subsequent analysis of the bonding in $\mathrm{Cr}\left(\eta^{6}-\mathrm{C}_{6} \mathrm{H}_{6}\right)_{2}$ suggests that chromium $\delta$-backdonation is the largest contributor to the bonding interactions. ${ }^{6}$

Not surprisingly, $\mathrm{Cr}\left(\eta^{6}-\mathrm{C}_{6} \mathrm{H}_{6}\right)_{2}$ has been the focus of several structural studies, providing valuable insights into metal bonding and chemistry. ${ }^{7}$ Notably, $\mathrm{Cr}\left(\eta^{6}-\mathrm{C}_{6} \mathrm{H}_{6}\right)_{2}$ is more than a simple curiosity as chromium mono- and bis(arene) complexes have become important reagents for organic synthesis and catalysis. ${ }^{8}$

Consequently, $\mathrm{Cr}\left(\eta^{6}-\mathrm{C}_{6} \mathrm{H}_{6}\right)_{2}$ has spawned a rich and diverse field of metal-arene chemistry spanning the $d$-block and growing to encompass the main group element series. ${ }^{9-10}$ On the other hand, glaringly lacking are metal-arene ${ }^{11}$ sandwich complexes belonging to the $4 f$ - and $5 f$-metals. Using electron-beam vaporization techniques, Cloke and co-workers accomplished the remarkable synthesis of a few, thermally stable homoleptic lanthanide-arene sandwich compounds of the type $\mathrm{Ln}\left(\eta^{6}{ }_{-}{ }^{t} \mathrm{Bu}_{3} \mathrm{C}_{6} \mathrm{H}_{3}\right)_{2}(\mathrm{Ln}=\mathrm{Nd}, \mathrm{Gd}, \mathrm{Tb}, \mathrm{Dy}, \mathrm{Ho}, \mathrm{Er}$, and $\mathrm{Lu})$ and the thermally unstable species $\mathrm{Ln}\left(\eta^{6}{ }_{-}{ }^{-} \mathrm{Bu}_{3} \mathrm{C}_{6} \mathrm{H}_{3}\right)_{2}(\mathrm{Ln}=\mathrm{La}, \mathrm{Pr}, \mathrm{Sm}) .{ }^{12-14}$ Electronic structure calculations show substantial lanthanide $d$ orbital $\rightarrow \pi^{*}$-arene backbonding. ${ }^{15-17}$ This is illuminating and surprising in many regards as the bonding of the lanthanide metals is typically considered to be predominantly ionic in nature, yet it is still possible for these metals to participate in covalent backbonding interactions through $5 d$-orbital contributions. Furthermore, the study validates the core-like nature of the $4 f$-orbitals and their unavailability for bonding. Though, in 2017, Mazzanti and coworkers reported the synthesis of the triple decker complex $[\mathrm{K}(2.2 .2 \text {-crypt })]_{2}\left\{\left[\left(\mathrm{KL}_{3} \mathrm{Ce}\right)\left(\mu-\eta^{6}: \eta^{6}-\mathrm{C}_{7} \mathrm{H}_{8}\right)\right]_{2} \mathrm{Ce}\right\}(\mathrm{L}=$ $\left.\mathrm{OSi}\left(\mathrm{O}^{t} \mathrm{Bu}\right)_{3}\right)$ from the reduction of $\left[\mathrm{KCeL}_{4}\right] .{ }^{18}$ This trinuclear compound features a cerium arene-sandwich $\left[\mathrm{Ce}\left(\eta^{6}-\right.\right.$ $\left.\left.\mathrm{C}_{7} \mathrm{H}_{8}\right)_{2}\right]^{2-}$ core, and DFT calculations show that each of the cerium atoms engages the toluene moieties through $\delta$ bonding involving the $4 f$-orbitals.

Homoleptic actinide-arene sandwich complexes would be particularly noteworthy and important for studying actinide bonding behavior as the $5 f$-orbitals extend beyond the core. Compounds such as these may give way to interesting molecules possessing exotic $\varphi$-type bonds. ${ }^{19-20}$ Understanding these types of molecules and their bonding character are important for addressing one of the more poorly understood areas of actinide science, namely the role and participation of the $5 f$ - and $6 d / 7 \mathrm{~s} / 7 p$-valence orbital combinations to chemical bonding. ${ }^{21}$

Yet, with respect to the actinides, all efforts to use similar vaporization techniques to produce the analogous An(arene $)_{2}$ compounds have failed, ${ }^{16}$ though gas-phase reactions have successfully detected the formation of [U( $\eta^{6}$ $\left.\left.{ }^{t} \mathrm{Bu}_{3} \mathrm{C}_{6} \mathrm{H}_{3}\right)_{2}\right]^{+}{ }^{22}$ suggesting an achievability for such molecules. In fact, quantum calculations predict $\mathrm{U}\left(\eta^{6}-\right.$ $\left.{ }^{t} \mathrm{Bu}_{3} \mathrm{C}_{6} \mathrm{H}_{3}\right)_{2}$ to have a metal-arene bond disruption enthalpy of $88 \mathrm{kcal} / \mathrm{mol}$, exceeding that of the analogous $\operatorname{Ln}\left(\eta^{6}-\right.$ $\left.{ }^{t} \mathrm{Bu}_{3} \mathrm{C}_{6} \mathrm{H}_{3}\right)_{2}(\mathrm{Ln}=\mathrm{Ce}-\mathrm{Yb})(28-72 \mathrm{kcal} / \mathrm{mol})$ and $\mathrm{M}\left(\eta^{6}-{ }^{t} \mathrm{Bu}_{3} \mathrm{C}_{6} \mathrm{H}_{3}\right)_{2}(\mathrm{M}=$ Group 4, Group 5; $49-79 \mathrm{kcal} / \mathrm{mol})$ complexes $;{ }^{17}$ though, the reliability of the calculated enthalpy value for uranium has been called into question due to the complicated electronic structure of the actinides. ${ }^{15}$

In 1970, Cesari et al. demonstrated that unsupported actinide-monoarene adducts could be accessed by applying Fischer's reductive Friedel-Crafts conditions used in the synthesis of $\mathrm{Cr}\left(\eta^{6}-\mathrm{C}_{6} \mathrm{H}_{6}\right)_{2}$. Specifically, the

treatment of $\mathrm{UCl}_{4}$ with an excess of $\mathrm{AlCl}_{3}$ and $\mathrm{Al}^{0}$ in benzene gives the $\mathrm{U}(\mathrm{III})$ complex $\left[\left(\eta^{6}-\mathrm{C}_{6} \mathrm{H}_{6}\right) \mathrm{U}\left(\mathrm{AlCl}_{4}\right)_{3}\right]^{23}$ Following a similar strategy, Cotton, Schwotzer, and others subsequently reported the synthesis and structural characterization of a handful of uranium-monoarene adducts including the first U(IV) arene complex $\left\{\left[\left(\eta^{6}-\right.\right.\right.$ $\left.\left.\left.\mathrm{C}_{6} \mathrm{Me}_{6}\right) \mathrm{UCl}_{2}\right]_{2}(\mu-\mathrm{Cl})_{3}\right\}\left[\mathrm{AlCl}_{4}\right] .{ }^{24-27}$ Later, Ephritikhine et al. showed that thermal decomposition of $\mathrm{U}\left(\mathrm{BH}_{4}\right)_{4}$ in mesitylene affords $\left(\eta^{6}-\mathrm{C}_{6} \mathrm{H}_{3} \mathrm{Me}_{3}\right) \mathrm{U}\left(\mathrm{BH}_{4}\right)_{3}$, which undergoes facile ligand displacement with hexamethylbenzene to give $\left(\eta^{6}-\mathrm{C}_{6} \mathrm{Me}_{6}\right) \mathrm{U}\left(\mathrm{BH}_{4}\right)_{3}{ }^{28}$ The $\mathrm{U}$-arene bonding in these complexes is likely to be electrostatic in nature with the neutral arene coordinating through the $\pi$-electron cloud as a Lewis base to the highly electron deficient uranium 
centers. Consequently, inspection of the $\mathrm{C}_{\text {aryl }}-\mathrm{C}_{\text {aryl }}$ distances reveals no bond length distortions, ${ }^{27}$ indicating a lack of metal backbonding, with the arene readily displaced by coordinating solvents such as THF. ${ }^{24}$ More recently, Braunschweig et al. reported the first actinide $\pi$-complexes with neutral 1,4-diborabenzene to give (dbb) $\mathrm{AnCl}_{4} \mathrm{~L}$ $\left(\mathrm{dbb}=1,4\right.$-bis $(\mathrm{cAAC})_{2}$-1,4-diborabenzene; $\left.\mathrm{An}=\mathrm{Th}, \mathrm{U} ; \mathrm{L}=\mathrm{THF}, \mathrm{MeCN}\right)$. In this case, the dbb-An bond was found to be very strong, though, also primarily electrostatic in character. ${ }^{29}$ In specific regards to thorium, Gambarotta and co-workers have reported the synthesis of the thorium naphthalene complexes $\left[\mathrm{Li}(\mathrm{DME})_{3}\right]\left\{[\mathrm{K}(\mathrm{DME})]\left[\left(\mathrm{Et}_{8}\right.\right.\right.$-calix$[4]$ tetrapyrrole $\left.\left.) \mathrm{Th}\left(\eta^{4}-\mathrm{C}_{10} \mathrm{H}_{8}\right)\right]\right\}, \quad\left\{[\mathrm{K}(\mathrm{DME})]\left[\left(\mathrm{Et}_{8}\right.\right.\right.$-calix$[4]$ tetrapyrrole $) \mathrm{Th}(\mu-$ $\left.\left.\left.\eta^{4}: \eta^{6}-\mathrm{C}_{10} \mathrm{H}_{8}-\mu-\mathrm{K}\right)\right]\right\}_{n}{ }^{30}$ and $\left[\mathrm{O}-2,4-{ }^{t} \mathrm{Bu}_{2}-\mathrm{C}_{6} \mathrm{H}_{2}\left(\mathrm{CH}_{2}\right)\right]_{2} \mathrm{Th}\left(\eta^{4}-\mathrm{C}_{10} \mathrm{H}_{8}\right)_{2}\left[\mathrm{~K}(18 \text {-crown-6) }]_{2}{ }^{31}\right.$ The latter is the only reported actinide-arene sandwich complex; however, low yields and persistent impurities prevented characterization beyond the determination of its solid-state molecular structure.

Compounds containing actinide-arene interactions have become increasingly important moieties in $5 f$-element chemistry. So called inverted sandwich complexes featuring An-arene-An cores have become nearly commonplace in uranium organometallic chemistry in recent years. ${ }^{32}$ These complexes have provided valuable electronic insight into actinide bonding, particularly with respect to $\delta$-interactions, while enabling rich redox chemistry and other novel reactivity patterns such as the $\mathrm{C}-\mathrm{H}$ borylation of arenes. ${ }^{32-44}$ For example, U(O-2,6- $\left.{ }^{t} \mathrm{Bu}_{2} \mathrm{C}_{6} \mathrm{H}_{3}\right)_{3}$ reacts with benzene in the presence of $\mathrm{HBBN}$ (HBBN = 9-bora-9-bicylononane) to give the inverted sandwich product [U(O2,6- $\left.\left.{ }^{t} \mathrm{Bu}_{2} \mathrm{C}_{6} \mathrm{H}_{3}\right)_{2}\right]_{2}\left[\mu: \eta^{6}: \eta^{6}-\mathrm{C}_{6} \mathrm{H}_{5}(\mathrm{BBN})\right]{ }^{43}$ Moreover, uranium-arene interactions play key roles in the stabilization of the rare $\mathrm{U}(\mathrm{II})$ oxidation state in $[\mathrm{K}(2.2 .2$-cryptand $)]\left\{\left[\left({ }^{\mathrm{Ad}, \mathrm{Me}} \mathrm{ArO}\right)_{3} \mathrm{Mes}\right] \mathrm{U}\right\} \quad\left(\left({ }^{\mathrm{Ad}, \mathrm{Me}} \mathrm{ArO}\right)_{3} \mathrm{Mes}=\kappa^{3}: \eta^{6}-\right.$ $\left.\mathrm{C}_{6} \mathrm{Me}_{3}\left[\mathrm{CH}_{2}\left(\mathrm{O}-\mathrm{C}_{6} \mathrm{H}_{2} \mathrm{MeAd}\right)\right]_{3}\right)^{45}$ and $\mathrm{U}\left(\kappa^{1}: \eta^{6}-\mathrm{NHAr}{ }^{i \mathrm{Pr} 6}\right)_{2}\left(\mathrm{Ar}^{i \mathrm{Pr} 6}=\left(2,4,6-{ }^{i} \mathrm{Pr}_{3} \mathrm{C}_{6} \mathrm{H}_{2}\right){ }_{2} \mathrm{C}_{6} \mathrm{H}_{3}\right),{ }^{46}$ where the uranium-arene bonds are enforced through intramolecular ligand tethering. Interestingly, it has been predicted by means of density functional theory (DFT) that uranium-arene complexes may also provide access to the unknown U(I) oxidation state. ${ }^{47}$

On this note, the use of tethered ligand manifolds to encourage supported actinide-arene interactions has become a popular approach within recent years. ${ }^{45-46,48-57}$ Bart, Meyer, and coworkers first demonstrated that uranium-arene $\delta$-bonding was a key feature of their U(III) complex $\left.\left[{ }^{t{ }^{\mathrm{Bu}}, t \mathrm{Bu}} \mathrm{ArO}\right)_{3} \mathrm{Mes}\right] \mathrm{U},{ }^{48}$ while Arnold and coworkers showed that redox isomerization of the trans-calix[2]benzene[2]pyrollide $\left(\mathrm{bz}_{2} \mathrm{pyr}_{2}{ }^{2-}\right)$ uranium complex gives rise to the supported sandwich compound $\left(\kappa^{2}-\eta^{6}: \eta^{6}-\mathrm{bz}_{2} \mathrm{pyr}_{2}\right) \mathrm{U}^{\mathrm{III}}(\mathrm{X})\left(\mathrm{X}=\mathrm{I}, \mathrm{BH}_{4}, \mathrm{O}-2,6-{ }^{t} \mathrm{Bu}_{2} \mathrm{C}_{6} \mathrm{H}_{3}, \mathrm{~N}\left(\mathrm{SiMe}_{3}\right)_{2}\right){ }^{52-53}$ In our own work, we have utilized an $N, N^{\prime}$-tethered uranium-arene platform, viz $\left[\left(\kappa^{2}: \eta^{6}-\mathrm{L}^{\mathrm{Ar}}\right) \mathrm{U}^{\mathrm{III}}\right]^{+}\left(\left(\mathrm{L}^{\mathrm{Ar}}\right)^{2-}=2,2^{\prime}-\right.$ bis $(2,6-$ $\left.{ }^{i} \mathrm{Pr}_{2} \mathrm{C}_{6} \mathrm{H}_{3} \mathrm{~N}\right)$-p-terphenyl), to stabilize an unusual U-Fe bond and separately generate a highly reactive uranium-

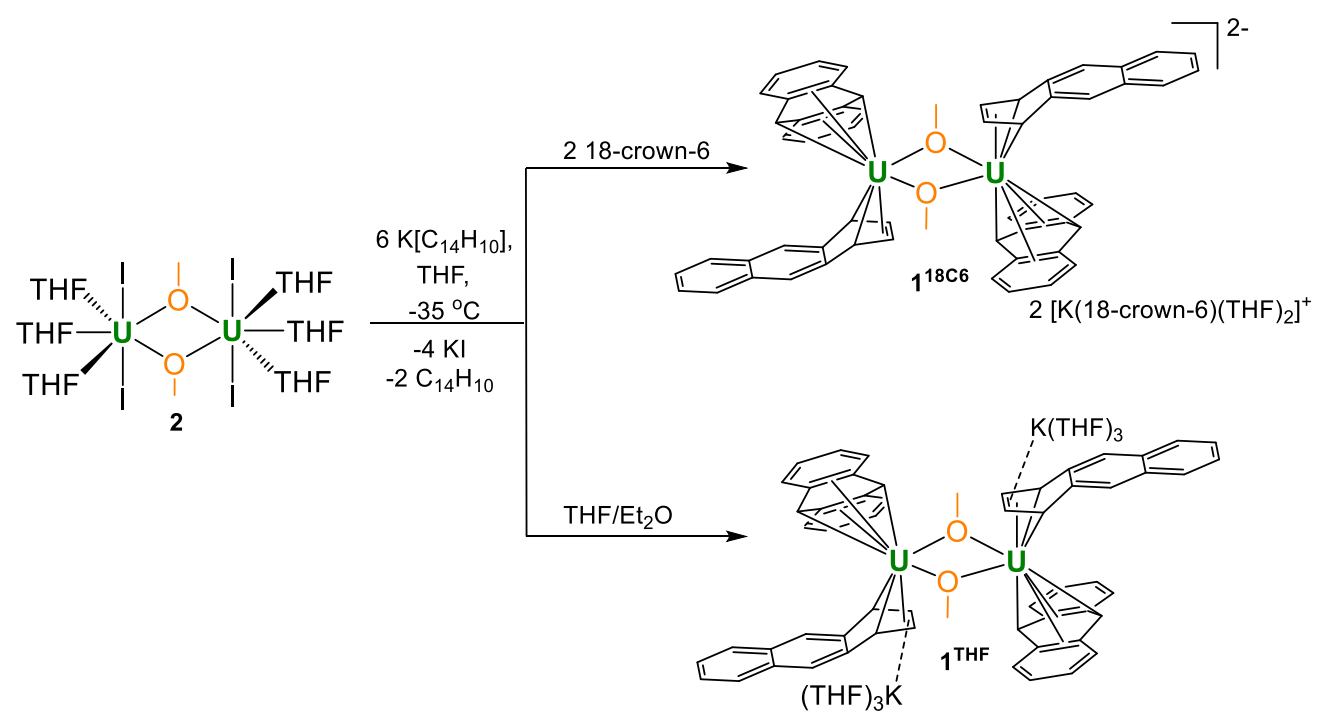

Scheme 1. Synthesis of complexes $\mathbf{1}^{18 \mathrm{C} 6}$ and $\mathbf{1}^{\mathrm{THF}}$ from 2. 
nitride species. ${ }^{55-56}$ Regardless, the ancillary ligand coordination in these systems provides additional bonding contributions and potential ligand strain effects that can compete with or affect the actinide-arene bonding.

Considering the soft nature of neutral aromatic hydrocarbons and the hard Lewis acidic character of the actinide ions, we hypothesized that the formation of unsupported $5 f$-sandwich arene complexes would be best accessed through the use of Chatt reaction conditions as popularized by Ellis and others. ${ }^{10}$ This method specifically refers to the reaction of a metal salt with a reduced arene anion to give metal-arene products through salt metathesis. The compounds produced in these reactions are often found to form "-ate" complexes, which have been referred to as "arene-metalates." 10

Through these means, we herein report the synthesis and characterization of the first unsupported uranium arenemetalate sandwich complexes, namely $\left[\mathrm{K}(18 \text {-crown-6)(THF })_{2}\right]_{2}\left[\mathrm{U}\left(\eta^{6}-\mathrm{C}_{14} \mathrm{H}_{10}\right)\left(\eta^{4}-\mathrm{C}_{14} \mathrm{H}_{10}\right)(\mu-\mathrm{OMe})\right]_{2} \cdot 4 \mathrm{THF}$ $\left(\mathbf{1}^{18 \mathrm{C}^{6}} \cdot 4 \mathrm{THF}\right)$ and ion contact paired $\left\{\left[\mathrm{K}(\mathrm{THF})_{3}\right]\left[\mathrm{U}\left(\eta^{6}-\mathrm{C}_{14} \mathrm{H}_{10}\right)\left(\eta^{4}-\mathrm{C}_{14} \mathrm{H}_{10}\right)(\mu-\mathrm{OMe})\right]\right\}_{2}\left(\mathbf{1}^{\mathrm{THF}}\right)$, formed from the reaction of excess $\mathrm{K}\left[\mathrm{C}_{14} \mathrm{H}_{10}\right]$ with the methoxy-iodide dimer $\left[\mathrm{UI}_{2}(\mathrm{THF})_{3}(\mu-\mathrm{OMe})\right]_{2}(\mathbf{2})$. Compounds $\mathbf{1}^{\mathbf{1 8 C}^{\mathbf{C}} \cdot 4 \mathrm{THF}}$ and $\mathbf{1}^{\text {THF }}$ are isolated in modest yields, and their structural and electronic properties have been thoroughly characterized through X-ray diffraction analysis, EPR spectroscopy, SQUID magnetometry, XANES spectroscopy, DFT, and multireference wavefunction-based computational methods. The magnetic and XANES data show a clear difference in the electronic properties of $\mathbf{1}^{\mathbf{1 8 C 6}} \cdot 4 \mathrm{THF}$ from $1^{\mathrm{THF}}$, revealing a key sensitivity of the electronic structure to coordination sphere ion pairing effects.

\section{Results and Discussion}

Synthesis. In one instance, addition of $\mathrm{UI}_{3}$ (dioxane) $)_{1.5}$ to a stirring solution of 6 equiv. of $\left.\mathrm{K}_{[14} \mathrm{C}_{10}\right]$ (prepared in-situ) in DME at $-35{ }^{\circ} \mathrm{C}$ produced an intensely dark blue solution. Filtration of the reaction mixture at room temperature afforded a dark blue solid that solubilized in THF to which excess 18-crown- 6 was added, resulting in the formation of a few single crystals after $12 \mathrm{~h}$ at $-35^{\circ} \mathrm{C}$. Single crystal X-ray diffraction analysis revealed the formation of the uranium bis(anthracene) sandwich dimer $\mathbf{1}^{\mathbf{1 8 C}} \cdot 4 \mathrm{THF}$ (Figures 1 and S2), with the units conjoined through two bridging methoxide ligands. The formation of the methoxide groups in $\mathbf{1}^{\mathbf{1 8 C 6}}$ was unexpected but is presumably formed from the reductive cleavage of the DME solvent, a phenomenon that is precedented in $f$-element

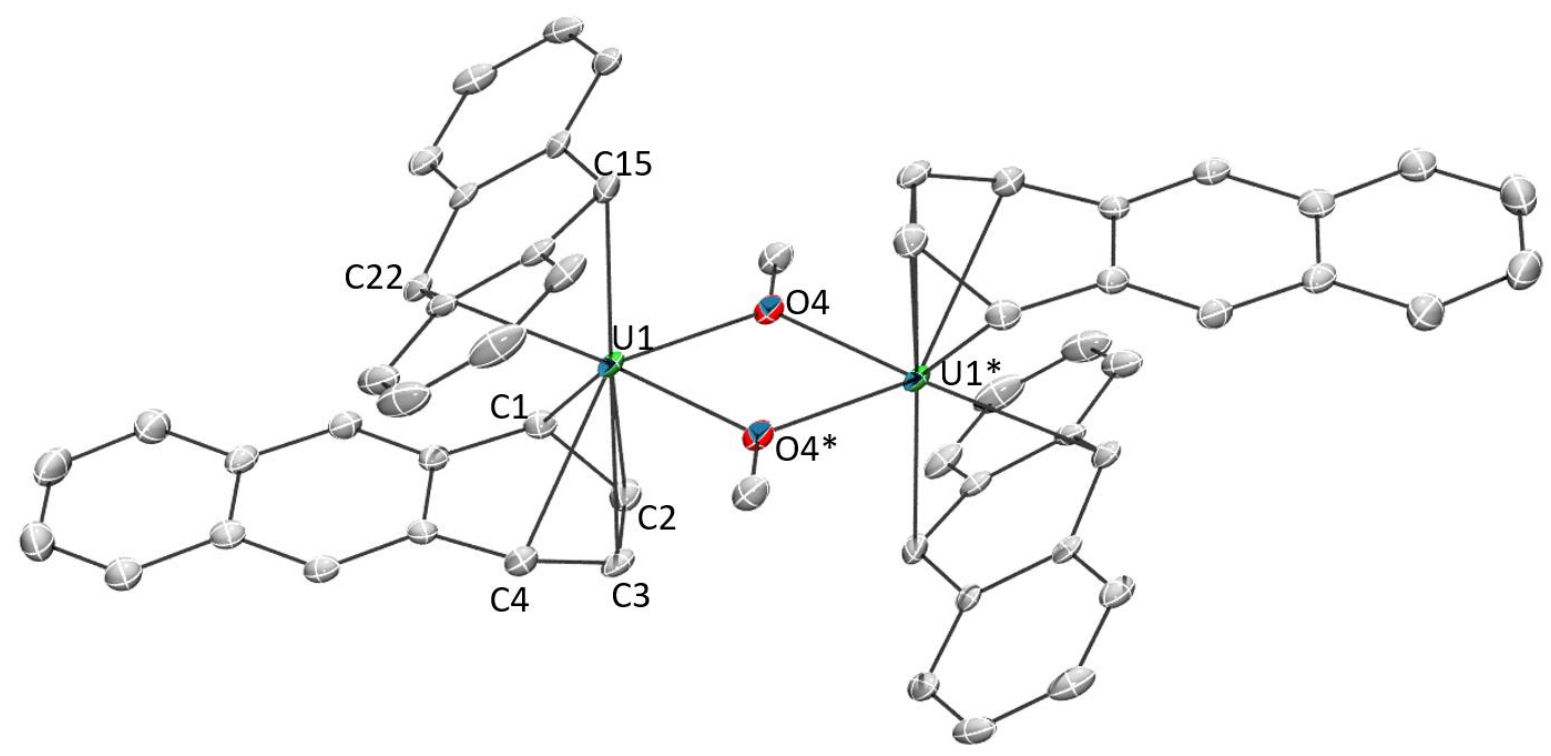

Figure 1. ORTEP diagram of $\mathbf{1}^{\mathbf{1 8 C 6}}$. $4 \mathrm{THF}$ with $30 \%$ thermal probability ellipsoids. Hydrogen atoms, co-crystallized THF, and the noncoordinated cations $\left(\left[\mathrm{K}(18-\text { crown- } 6)(\mathrm{THF})_{2}\right]^{+}\right)$are omitted for clarity. * denote symmetry generated atom positions. 
reduction chemistry. ${ }^{58-60}$ Multiple attempts to reproduce this synthesis failed, giving $[\mathrm{K}(18$-crown6)(THF $\left.)_{2}\right]\left[\mathrm{C}_{14} \mathrm{H}_{10}\right]^{61}$ as the only isolable product.

We postulate that the uncontrolled reductive cleavage of the reaction solvent to form the methoxy ligands of $\mathbf{1}^{18 \mathrm{C} 6}$ is primarily responsible for the irreproducibility of the reaction and therefore set out to pre-install the methoxy groups on uranium prior to $\mathrm{K}\left[\mathrm{C}_{14} \mathrm{H}_{10}\right]$ addition. Adding one equiv. of $\mathrm{K}[\mathrm{OMe}]$ to $\mathrm{UI}_{3}$ (dioxane) $)_{1.5}$ in $\mathrm{THF}$ gives $\mathbf{2} \cdot$ THF as a blue crystalline solid upon workup in $60 \%$ yield (Equation 1) (Figure S1).

This uranium(III) methoxy-bridged precursor, 2, proved ideal as conversion to $\mathbf{1}^{\mathbf{1 8 C 6}}$ can be accomplished directly through salt metathesis, thus avoiding the necessity for adventitious DME cleavage. Addition of $\mathbf{2} \cdot \mathrm{THF}$ to a cold, stirring solution of 6 equiv. of $\mathrm{K}\left[\mathrm{C}_{14} \mathrm{H}_{10}\right]$ in THF followed by filtration and addition of 2 equiv. of 18crown-6 reproducibly generates $\mathbf{1}^{\mathbf{1 8 C 6}} \cdot 4 \mathrm{THF}$ in modest yields of $35 \%$ as a highly crystalline, midnight-blue colored product (Scheme 1). Forgoing the use of 18-crown6 produces the THF-solvated complex $\mathbf{1}^{\text {THF }}$ in comparable yields (Scheme 1) (Figure S6). In these reactions, 2 equiv. of anthracene are also produced that can co-deposit in the product mixture. Yet, after crystallization, both $\mathbf{1}^{18 \mathrm{C} 6} \cdot 4 \mathrm{THF}$ and $\mathbf{1}^{\mathrm{THF}}$ exhibit insolubility in DME and THF with the residual anthracene readily removed by thorough washing of the crystalline material with THF to give analytically pure products as shown by combustion analyses. These compounds are also insoluble in non-polar solvents and aromatics such as toluene.

Compounds $\mathbf{1}^{18 \mathrm{C6}}$. $4 \mathrm{THF}$ and $\mathbf{1}^{\mathrm{THF}}$ are exceedingly air-sensitive, instantaneously bleaching in color upon exposure. On the other hand, they are thermally stable as solids and can be stored indefinitely under dinitrogen or argon atmospheres. Suspensions of isolated samples of $\mathbf{1}^{\mathbf{1 8 C 6}} \cdot 4 \mathrm{THF}$ and $\mathbf{1}^{\mathrm{THF}}$ in THF are unstable, and despite their insolubility, will gradually decompose (under $\mathrm{N}_{2}$ or $\mathrm{Ar}$ ) to give black insoluble material and dark blue solutions with $\mathrm{K}\left[\mathrm{C}_{14} \mathrm{H}_{10}\right]$ as the only product detectable by electronic absorption spectroscopy (UV-vis/NIR). This solution-phase instability suggests that $\mathbf{1}^{\mathbf{1 8 C 6}} \cdot 4 \mathrm{THF}$ and $\mathbf{1}^{\mathrm{THF}}$ are likely the kinetic products of the reaction.

The solid-state molecular structures of $\mathbf{1}^{\mathbf{1 8 C 6}}$.4THF (Figures 1 and S2) and $\mathbf{1}^{\text {THF }}$ (Figure S6) are nearly isostructural with the differences arising from the potassium ion pairing, yielding a charge-separated, non-interacting pair in the former and a close contact pair in the latter, possessing $\mathrm{K}-\mathrm{C}_{\text {arene }}$ interactions. Otherwise, both complexes feature a $\left\{\left[\mathrm{U}\left(\eta^{6}-\mathrm{C}_{14} \mathrm{H}_{10}\right)\left(\eta^{4}-\mathrm{C}_{14} \mathrm{H}_{10}\right)(\mu-\mathrm{OMe})\right]_{2}\right\}^{2-}$ dimeric core. By far, the most salient feature of $\mathbf{1}^{18 \mathbf{C 6}} \cdot 4 \mathrm{THF}$ and $\mathbf{1}^{\text {THF }}$ is the sandwiching of each uranium center between two anthracene units that are observed to adopt distinct $\eta^{4}$ - and $\eta^{6}$-coordination. The mixed binding modes of the anthracenes is an uncommon feature for electronically unsaturated bis(arene)-metalates and, to the best of our knowledge, has been documented in only a few cases. ${ }^{62-64}$

$$
\mathrm{UI}_{3}(\text { dioxane })_{1.5}+\mathrm{KOMe} \underset{-\mathrm{KI}}{\stackrel{\mathrm{THF}, \mathrm{RT}}{\longrightarrow}} 0.5\left[\mathrm{UI}_{2}(\mathrm{THF})_{3}(\mu-\mathrm{OMe})\right]_{2}
$$


The solid-state molecular structure of $\mathbf{1}^{\text {THF }}$ is afflicted with severe positional disorder of its potassium-coordinated THF molecules, consequently affecting the data quality, leading to slightly reduced precision of the bond metrics. Therefore, only the structural features of $\mathbf{1}^{\mathbf{1 8 C 6}}$. $4 \mathrm{THF}$ are discussed here in detail.

Complex $1^{18 \mathrm{C} 6}$. $4 \mathrm{THF}$ crystallizes in the triclinic space group $P \overline{1}$ with one half of the molecule in the asymmetric unit, generating the full complex through crystallographic inversion symmetry, rendering the metrics within the monomeric units identical. The U1- $\left(\eta^{4}-\mathrm{C}_{\text {arene }}\right)$ distances narrowly range from $2.638(5)$ to $2.676(6) \AA$. Tetrahapto coordination of aromatic or carbocyclic ligands to the actinides is rare, but a handful of cyclobutadiene complexes are known. The U1- $\left(\eta^{4}-\mathrm{C}_{\text {arene }}\right)$ distances in $\mathbf{1}^{\mathbf{1 8 C 6}} \cdot 4 \mathrm{THF}$ are significantly longer than the uranium-cyclobutadiene distances found in $\left[\mathrm{Na}(12 \text {-crown-4) })_{2}\right]\left\{\left[\eta^{4}-\mathrm{C}_{4}\left(\mathrm{SiMe}_{3}\right)_{4}\right] \mathrm{U}\left(\mathrm{BH}_{4}\right)_{3}\right\}\left(\mathrm{U}-\mathrm{C}_{\mathrm{Cb}}=2.522(5)-2.556(4) \AA\right)$ and $\left\{\mathrm{U}\left[\eta^{4}-\right.\right.$ $\left.\left.\mathrm{C}_{4}\left(\mathrm{SiMe}_{3}\right)_{4}\right]\left(\mu-\mathrm{BH}_{4}\right)_{3}\left[\mathrm{~K}(\mathrm{THF})_{2}\right]\right\}_{2}\left(\mathrm{U}-\mathrm{C}_{\mathrm{Cb}}=2.46(2)-2.56(2) \AA\right)$ but fall within the upper range of those in $\left\{\mathrm{U}\left[\eta^{4}-\right.\right.$ $\left.\left.\mathrm{C}_{4}\left(\mathrm{SiMe}_{3}\right)_{4}\right]\left[\eta^{3}-\mathrm{C}_{4} \mathrm{H}\left(\mathrm{SiMe}_{3}\right)_{3}-\kappa-\mathrm{CH}_{2} \mathrm{SiMe}_{2}\left(\mathrm{BH}_{4}\right)\right]\right\}^{-}\left(\mathrm{U}-\mathrm{C}_{\mathrm{Cb}}=2.550(5)-2.650(6) \AA\right) .{ }^{65}$ Closer comparison can be made to the thorium compound $\left\{\left[\mathrm{O}-2,4-{ }^{t} \mathrm{Bu}_{2}-\mathrm{C}_{6} \mathrm{H}_{2}\left(\mathrm{CH}_{2}\right)\right]_{2} \mathrm{Th}\left(\eta^{4}-\mathrm{C}_{10} \mathrm{H}_{8}\right)_{2}\right\}\left[\mathrm{K}(18 \text {-crown-6) }]_{2}\right.$ which features Th$\mathrm{C}_{\text {arene }}$ bonds that range from 2.671(8) to 2.784(8) $\AA,{ }^{31}$ where the elongation of the thorium-arene distances as compared to $1^{18 \mathrm{C} 6}$. $4 \mathrm{THF}$ possibly result from the slight size difference in the ionic radii between thorium and uranium (e.g., Th(IV), C.N. =6, r = $0.94 \AA$ vs. U(IV), C.N. $=6, r=0.89 \AA) .{ }^{66}$

Inspection of the U1- $\left(\eta^{6}-\mathrm{C}_{\text {arene }}\right)$ distances reveals two sets of bond lengths, two shorter $\left(\mathrm{U} 1-\mathrm{C}_{\text {arene }}=2.557(5)-\right.$ $2.571(6) \AA$ ) and four longer (U1- $\left.C_{\text {arene }}=2.766(5)-2.797(5) \AA\right)$, that differ by approximately $0.2 \AA$, a consequence of the observed ring puckering of the anthracene ligand (vide infra). The range of the $\mathrm{U} 1-\mathrm{C}_{\text {arene }}$ distances along with the nominal uranium-centroid distance $\mathrm{U} 1-\left(\eta^{6}-\mathrm{C}_{\text {cent }}\right)=2.31 \AA$ of $\mathbf{1}^{\mathbf{1 8} \mathbf{C 6}} \cdot 4 \mathrm{THF}$ are significantly shorter than those found in the monoarene Friedel-Crafts type complexes $\left[\left(\eta^{6}-\mathrm{C}_{6} \mathrm{H}_{6}\right) \mathrm{U}\left(\mathrm{AlCl}_{4}\right)_{3}\right]\left(\mathrm{U}-\mathrm{C}_{\text {cent }}=2.56 \AA\right.$, avg. U-C $\mathrm{C}_{\text {arene }}$ $=2.91 \AA)$ and $\left\{\left[\left(\eta^{6}-\mathrm{C}_{6} \mathrm{Me}_{6}\right) \mathrm{UCl}_{2}\right]_{2}(\mu-\mathrm{Cl})_{3}\right\}\left[\mathrm{AlCl}_{4}\right]$ (avg. U-C $\mathrm{C}_{\text {cent }}=2.55 \AA$, avg. U-C $\left.\mathrm{C}_{\text {arene }}=2.92 \AA\right) .{ }^{23-24}$ Comparison to inverted sandwich complexes, ${ }^{32}$ namely the organometallic inverted benzene sandwich $\left(\mathrm{Cp} *{ }_{2} \mathrm{U}\right)_{2}\left(\mu-\eta^{6}: \eta^{6}-\mathrm{C}_{6} \mathrm{H}_{6}\right)$ $\left(\mathrm{Cp}^{*}=\eta^{5}-\mathrm{C}_{5} \mathrm{Me}_{5}\right){ }^{42}$ possessing a puckered benzene ring, shows an avg. $\mathrm{U}-\mathrm{C}_{\text {cent }}=2.20 \AA$ distance that is sizably shorter than $\mathbf{1}^{18 \mathrm{C} 6}$. $4 \mathrm{THF}$ but with a comparable $\mathrm{U}-\mathrm{C}_{\text {arene }}=2.51(1)-2.73(1) \AA$ bond range. The shorter $\mathrm{U}-\mathrm{C}_{\text {arene }}$ distances in $\mathbf{1}^{18 \mathrm{C} 6}$. $4 \mathrm{THF}$, as compared to $\left[\left(\eta^{6}-\mathrm{C}_{6} \mathrm{H}_{6}\right) \mathrm{U}\left(\mathrm{AlCl}_{4}\right)_{3}\right]$ and $\left\{\left[\left(\eta^{6}-\mathrm{C}_{6} \mathrm{Me}_{6}\right) \mathrm{UCl}_{2}\right]_{2}(\mu-\mathrm{Cl})_{3}\right\}\left[\mathrm{AlCl}_{4}\right]$ with their neutral arene ligands, suggests a strong bonding interaction that may be due to increased charge accumulation within the anthracene moieties. As such, the $\mathrm{U}_{-} \mathrm{C}_{\text {arene }}$ bond metrics in $\mathbf{1}^{\mathbf{1 8 C 6}} \cdot 4 \mathrm{THF}$ better match the parameters of $\left(\mathrm{Cp}^{*}{ }_{2} \mathrm{U}\right)_{2}\left(\mu-\eta^{6}: \eta^{6}-\mathrm{C}_{6} \mathrm{H}_{6}\right)$, where the bridging benzene moiety is assigned a dianionic charge.

In line with this, both the $\eta^{6}-\mathrm{C}_{14} \mathrm{H}_{10}$ and $\eta^{4}-\mathrm{C}_{14} \mathrm{H}_{10}$ rings of $\mathbf{1}^{\mathbf{1 8 C} \mathbf{6}} \cdot 4 \mathrm{THF}$ show distortions from planarity (Figure 2a), which is typically considered an indication of localized anionic charge character in monometallic arene-metalate systems. ${ }^{67}$ For instance, in magnesium anthracenides featuring $\left(\mathrm{C}_{14} \mathrm{R}_{10}\right)^{2-}$, the central ring fold angles are $28.6^{\circ}$ in $\left[\mathrm{Mg}\left(\eta^{2}-\mathrm{C}_{14} \mathrm{H}_{10}\right)(\mathrm{THF})_{3}\right]$ and $41.0^{\circ}$ in $\left[\mathrm{Mg}\left(\eta^{2}-1,4-\mathrm{Me}_{2} \mathrm{C}_{14} \mathrm{H}_{8}\right)(\mathrm{THF})_{3}\right] .{ }^{68-69}$ Along these lines, a few examples of mononuclear $4 f$-element anthracene complexes are known, and they too show similar folding ( $\mathrm{cf}$. $\mathrm{CpLu}\left(\eta^{2}\right.$ $\left.\left.\mathrm{C}_{14} \mathrm{H}_{10}\right),{ }^{70} 35.8^{\circ} ;\left(\eta^{2}-\mathrm{C}_{14} \mathrm{H}_{10}\right) \mathrm{TmI}(\mathrm{DME})_{2},{ }^{71} 37.8^{\circ}\right)$. In comparison, the $\eta^{6}-\mathrm{C}_{14} \mathrm{H}_{10}$ ligand in $\mathbf{1}^{18 \mathrm{C} 6} \cdot 4 \mathrm{THF}$ shows a shallow bend angle of $18.8^{\circ}$ across the central, bridgehead C15/C22 bond vector (Figures $2 \mathrm{a}$ and S2). The more acute folding of the anthracene ring in $\mathbf{1}^{18 \mathrm{C} 6}$. $4 \mathrm{THF}$ suggests carbon atom hybridization at $\mathrm{C} 15$ and $\mathrm{C} 22$ that is closer to $s p^{2}$-character. In support of this idea, the fold angle in dibenzo-7-dimethylgermanobornadiene $\left(\mathrm{Me}_{2} \mathrm{GeA} ; \mathrm{A}=\right.$ $\left.\mathrm{C}_{14} \mathrm{H}_{10}\right)$ is $56.8^{\circ}$, wherein the germanium atom is bound to $s p^{3}$-hybridized bridgehead carbons. ${ }^{72}$ In addition, the $\eta^{4}-\mathrm{C}_{14} \mathrm{H}_{10}$ ligand of $\mathbf{1}^{\mathbf{1 8 C} \mathbf{C}}$. $4 \mathrm{THF}$ exhibits a bend angle of $26.8^{\circ}$ from planarity at its terminal, coordinating ring. Similar $\eta^{4}-\mathrm{C}_{14} \mathrm{H}_{10}$ bending has been observed in a number of complexes, ${ }^{10}$ and the deviation from planarity is comparable to that found in the bis(anthracene) niobium compound $\left\{\left[\mathrm{K}(18\right.\right.$-crown-6)(THF) $]\left(\eta^{4}-\right.$ $\left.\left.\mathrm{C}_{14} \mathrm{H}_{10}\right)_{2} \mathrm{Nb}\left[\mathrm{P}(\mathrm{OMe})_{3}\right]_{2}\right\}\left(28.4^{\circ}\right) .^{73}$

The structural distortion of these arene rings can be accounted through localized population of C-C $\pi^{*}$-orbitals. Consequently, it would be expected that formal reduction of the anthracene ring should also manifest in elongated $\mathrm{C}-\mathrm{C}$ bonds; though, in uranium inverted sandwich complexes, it is not unusual to find planar, bridging arenides with little to no obvious $\mathrm{C}-\mathrm{C}$ bond lengthening. ${ }^{32}$

Inspection of the $\mathrm{C}-\mathrm{C}$ bond lengths within the $\eta^{6}-\mathrm{C}_{14} \mathrm{H}_{10}$ and $\eta^{4}-\mathrm{C}_{14} \mathrm{H}_{10}$ rings of $\mathbf{1}^{18 \mathrm{C} 6}$. $4 \mathrm{THF}$ shows obvious bond distance perturbations as compared to neutral, aromatic anthracene, ${ }^{74}$ and the $\mathrm{C}-\mathrm{C}$ ring distances of $\mathbf{1}^{\mathbf{1 8 C} 6} \cdot 4 \mathrm{THF}$ are 
shown in Figure $2 \mathrm{~b}$. In the case of $\eta^{6}-\mathrm{C}_{14} \mathrm{H}_{10}$, the $\mathrm{C}-\mathrm{C}$ bond distances of the central, coordinated ring narrowly range from $1.429(9)$ to $1.456(8) \AA$ with an average distance of $1.44 \AA$, which is slightly longer than the average $\mathrm{C}$ $\mathrm{C}$ distances within the peripheral rings, both $1.40 \AA$, the latter falling nicely within the expected C-C bond length of $1.41 \AA$ for aromatic hydrocarbon bonds. ${ }^{75}$ The slight elongations are consistent with formal reduction of the $\eta^{6}$ $\mathrm{C}_{14} \mathrm{H}_{10}$ ligand and, as such, compares favorably with the corresponding C-C distances of $\left[\mathrm{Mg}\left(\mathrm{C}_{14} \mathrm{H}_{10}\right)(\mathrm{THF})_{3}\right](\mathrm{C}-$ $\mathrm{C}=1.42(2)-1.49(2) \AA$, avg. $1.45 \AA)$ and $\mathrm{CpLu}\left(\eta^{2}-\mathrm{C}_{14} \mathrm{H}_{10}\right)(\mathrm{C}-\mathrm{C}=1.43(1)-1.47(2) \AA$, avg. $1.45 \AA)$. Turning to the $\eta^{4}-\mathrm{C}_{14} \mathrm{H}_{10}$ ring, the bond distances of the coordinated carbon atoms are $\mathrm{C} 1-\mathrm{C} 2=1.441(8) \AA ; \mathrm{C} 2-\mathrm{C} 3=1.371(8)$ $\AA$; and C3-C4 = 1.438(8) $\AA$ with the three adjoining, non-coordinating bonds ranging from 1.452(9) - 1.466(7) $\AA$, while the remaining $\mathrm{C}-\mathrm{C}$ distances of the $\eta^{4}-\mathrm{C}_{14} \mathrm{H}_{10}$ ring conform to standard aromatic bond lengths (avg. $1.39 \AA$ ). (Note that the pattern in the bond distances is present in the DFT geometries (Table S15), vide infra.) This longshort-long bond pattern of the $\mathrm{C} 2$ to $\mathrm{C} 4$ moiety is consistent with a localized '-ene' dianion form having the charge centers at $\mathrm{C} 1$ and $\mathrm{C} 4$. Yet, while the structural parameters clearly indicate negative charge accumulation on the coordinated $\eta^{6}-\mathrm{C}_{14} \mathrm{H}_{10}$ and $\eta^{4}-\mathrm{C}_{14} \mathrm{H}_{10}$ rings, the ability of anthracene to access and sustain both monoanionic and dianionic forms complicates the charge picture.

EPR. In an effort to better define the charge states and assess the electronic structure of the uranium bis(anthracene) compounds, X-band EPR measurements were performed on powdered samples of $\mathbf{1}^{18 \mathrm{C} 6} \cdot 4 \mathrm{THF}$ and $\mathbf{1}^{\mathrm{THF}}$ at 4 $( \pm 1) \mathrm{K}$. In these samples, a strong and clear isotropic signal centered at $g=2.000$ for $\mathbf{1}^{\mathrm{THF}}$ and $\mathrm{g}=2.017$ for $\mathbf{1}^{\mathbf{1 8 C 6}}$. 4THF is observed (Figures S10 and S11), consistent with isolated S $=1 / 2$ spins. These peaks persist at roomtemperature, retaining their relative signal intensity, and point to the presence of an anthracene-based radical in both complexes with the slightly larger g-value of $\mathbf{1}^{18 \mathrm{C} 6}$. $4 \mathrm{THF}$ indicating modest metal-orbital contribution. Similar EPR spectra have been observed in arene-metalates such as $\left[\mathrm{K}\left(18\right.\right.$-crown-6)] $\left[\mathrm{Cr}_{2}\left(\mathrm{C}_{10} \mathrm{H}_{8}\right)_{2}\right](\mathrm{g}=1.987)$ where the radical is largely localized on the arene ligand. ${ }^{64}$ Resonances corresponding to uranium-based signals were not observed.

The appearance of the EPR signals for $\mathbf{1}^{18 \mathrm{C} 6}$. $4 \mathrm{THF}$ and $\mathbf{1}^{\mathrm{THF}}$ definitively establishes negative charge states within the anthracene ligands but provides only a general picture. For instance, the observed EPR resonances are at odds with a closed-shell $\left(\mathrm{C}_{14} \mathrm{H}_{10}\right)^{2-}$ ligand form, suggesting $\left(\mathrm{C}_{14} \mathrm{H}_{10}\right)^{-\bullet}$ radical monoanion character in at least one of the coordinated anthracenes; however, this must be taken with caution as it has been shown that anthracene dianions do have accessible triplet excited states where the population energies are heavily dependent on the character of the counterion, solvent, and temperature. ${ }^{76}$

Magnetic Susceptibility. To provide further insight into the paramagnetic character of these complexes, magnetic susceptibility studies were performed on crushed polycrystalline samples of $\mathbf{1}^{\mathbf{1 8 C} \mathbf{6}} \cdot 4 \mathrm{THF}$ and $\mathbf{1}^{\mathrm{THF}}$ using SQUID magnetometry in the temperature range of $1.8-300 \mathrm{~K}$ at $0.1 \mathrm{~T}$. A plot of the effective magnetic moment $\left(\mu_{\text {eff }}\right)$ verses temperature is shown in Figure 3. The data for $\mathbf{1}^{18 \mathrm{C} 6}$. $4 \mathrm{THF}$ and $\mathbf{1}^{\mathrm{THF}}$ follow a similar trend as the $\mu_{\mathrm{eff}}$ gradually decreases as a function of temperature, curving downwards to 0.80 and $0.43 \mu_{\mathrm{B}}$ at $1.8 \mathrm{~K}$, respectively. Curiously, despite their structural similarity at uranium, the overall $\mu_{\text {eff }}$ values for $\mathbf{1}^{\text {THF }}$ are lower than that of $\mathbf{1}^{\mathbf{1 8 C 6}}$.4THF. For instance, at $300 \mathrm{~K}, \mathbf{1}^{\mathbf{1 8 C 6}}$. 4THF and $\mathbf{1}^{\mathrm{THF}}$ exhibit $\mu_{\text {eff }}$ values of $4.40 \mu_{\mathrm{B}}$ and $3.74 \mu_{\mathrm{B}}$, respectively, with a sizable $\Delta\left(\mu_{\mathrm{eff}}\right)=0.66 \mu_{\mathrm{B}}$ at room temperature that reduces to $\Delta\left(\mu_{\mathrm{eff}}\right)=0.37 \mu_{\mathrm{B}}$ at lower temperatures. This indicates that the contact pairing of the potassium cations plays a critical role in the modulation of the electronic structure of the $\left\{\left[\mathrm{U}\left(\eta^{6}-\mathrm{C}_{14} \mathrm{H}_{10}\right)\left(\eta^{4}-\mathrm{C}_{14} \mathrm{H}_{10}\right)(\mu-\mathrm{OMe})\right]_{2}\right\}^{2-}$ cores in $\mathbf{1}^{\mathbf{1 8 C 6}}$ and $\mathbf{1}^{\mathbf{T H F}}$. We postulate that the Lewis acidity of the contact-paired potassium cations in $\mathbf{1}^{\mathrm{THF}}$ polarizes and concentrates electron density onto the coordinated portion of the $\eta^{4}$-anthracene ligands, thus giving rise to point charge accumulation that leads to a stronger crystal field splitting effect, and consequently lower $\mu_{\text {eff }}$ for $\mathbf{1}^{\text {THF }}$. This enhanced charge buildup is supported by analyzing DFT atomic charges as discussed below (see Electronic Structure Analysis).

Qualitatively, the curvatures of both magnetization plots in Figure 3 are characteristic of U(IV) complexes that approach singlet ground states upon cooling to low temperatures due to thermal depopulation of the metal excited 
states. $^{77-78}$ However, the $\mu_{\text {eff }}$ of $\mathbf{1}^{\mathbf{1 8 C 6}} \cdot 4 \mathrm{THF}$ $\left(4.40 \mu_{\mathrm{B}}\right)$ and $\mathbf{1}^{\mathrm{THF}}\left(3.74 \mu_{\mathrm{B}}\right)$ at $300 \mathrm{~K}$, possible ligand radical contributions aside, are much lower than the expected $\mu_{\text {eff }}=5.06 \mu_{\mathrm{B}}$ for a $\mathrm{U}(\mathrm{IV})$ dimer $\left(3.58 \mu_{\mathrm{B}}\right.$ per $5 f^{2},{ }^{3} \mathrm{H}_{4}$ ion) with magnetically isolated metal centers. ${ }^{77-78}$ In relation to inverted sandwich complexes, the $\mu_{\text {eff }}$ of $\mathbf{1}^{\mathbf{1 8 C}}$.4THF and $\mathbf{1}^{\mathrm{THF}}$ are higher than those found for $\left(\mathrm{Cp}^{*}{ }_{2} \mathrm{U}^{\mathrm{III}}\right)_{2}\left(\mu-\eta^{6}: \eta^{6}-\mathrm{C}_{6} \mathrm{H}_{6}\right)\left(\mu_{\mathrm{eff}}=2.1\right.$ $\left.\mu_{\mathrm{B}}\right),{ }^{42}\left[\mathrm{~K}_{2}\left\{\mathrm{U}^{\mathrm{IV}}\left[\mathrm{OSi}\left(\mathrm{O}^{t} \mathrm{Bu}\right)_{3}\right]_{3}\right\}_{2}\left(\mu-\eta^{6}: \eta^{6}-\mathrm{C}_{7} \mathrm{H}_{8}\right)\right]$ $\left(\mu_{\mathrm{eff}}=2.23 \mu_{\mathrm{B}}\right),{ }^{40}$ and $\left[\left\{\mathrm{HC}\left[\mathrm{SiMe}_{2} \mathrm{~N}(4-\right.\right.\right.$ $\left.\left.\left.\left.\mathrm{MeC}_{6} \mathrm{H}_{4}\right)\right]_{3}\right\} \mathrm{U}^{\mathrm{V}}\right]_{2}\left(\mu-\eta^{6}: \eta^{6}-\mathrm{C}_{7} \mathrm{H}_{8}\right) \quad\left(\mu_{\text {eff }}=3.32\right.$ $\left.\mu_{\mathrm{B}}\right)^{39}$ at room temperature. Moreover, factoring in potential ligand radical contributions, while maintaining U(IV) assignments, gives near room temperature calculated values that range from $\mu_{\text {eff }}=5.35 \mu_{\mathrm{B}}$ (one ligand radical) to $\mu_{\mathrm{eff}}=$ $6.14 \mu_{\mathrm{B}}$ (four, non-interacting ligand radicals) and higher. The analysis is further confounded by the fact that $\mu_{\mathrm{eff}}$ values for uranium are highly variable, ${ }^{77}$ and this does not factor in possible uranium superexchange and other magnetic coupling interactions between spin carriers. In comparison to the U(IV) dimer $\left[\left({ }^{\mathrm{Mes}} \mathrm{PDI}^{\mathrm{Me}}\right) \mathrm{U}^{\mathrm{IV}} \mathrm{I}_{2}\left({ }^{\mathrm{Mes}} \mathrm{PDI}^{\mathrm{Me}}=\left[2,6-(\mathrm{MesN}=\mathrm{CMe})\left(\mathrm{NC}_{5} \mathrm{H}_{3}\right)^{\bullet}\right]^{3-}\right)\right.$ possessing ligand-centered PDI-radicals, its $\mu_{\text {eff }}$ displays a much narrower range from $\mu_{\mathrm{eff}}=1.03-2.66 \mu_{\mathrm{B}}(2-300 \mathrm{~K})$, where the low temperature $\mu_{\mathrm{eff}}$ is said to derive from the unquenched spins of the ligand radicals.

XANES. Given the difficulty of definitively assigning charge states to the ligands and uranium centers for $\mathbf{1}^{18 \mathrm{C} 6}$. $4 \mathrm{THF}$ and $\mathbf{1}^{\mathrm{THF}}$ based upon the intermediacy of the structural parameters and magnetism data, transmission mode $\mathrm{U}_{\mathrm{III}}$-edge X-ray absorption near edge spectroscopy (XANES) measurements were performed at room temperature. The samples consisted of pulverized, compressed pellets of $\mathbf{1}^{18 \mathrm{C} 6} \cdot 4 \mathrm{THF}$ and $\mathbf{1}^{\mathrm{THF}}$ diluted in X-ray transparent boron nitride matrices vacuum sealed under an argon atmosphere in polyethylene envelopes (see Supporting Information for further detail).

XANES spectroscopy has become an effective tool for the delineation of metal oxidation states in actinide compounds. ${ }^{37-38,79-82}$ With regards to uranium, the $\mathrm{U} \mathrm{L}_{\mathrm{III}}$-edge energy corresponds to an electric-dipole allowed $\left(2 p^{6} 3 d^{10}\right) 5 f^{\prime} 6 d^{0} \rightarrow\left(2 p^{5} 3 d^{10}\right) 5 f^{n} 6 d^{1}$ photoexcited core electron transition, ${ }^{79,81}$ where the excitation energy is dependent upon the shielding environment of the $2 p$-electrons and their relative binding energies, providing insights into the effective nuclear charge of the uranium. Consequently, the X-ray absorption energy correlates to the charge character of the absorbing uranium ion, allowing for formal oxidation state assignments. This can be quantified through the absorption threshold of the edge energy, defined as the inflection point in the first derivative of the XANES spectrum, as well as the peak "white line" energy.

The background-subtracted and intensity normalized XANES spectra for $\mathbf{1}^{18 \mathrm{C} 6} \cdot 4 \mathrm{THF}$ and $\mathbf{1}^{\mathrm{THF}}$ is presented in Figure $4 \mathrm{a}$ and is plotted alongside spectra collected for the respective U(III)-U(VI) standards $\mathrm{UI}_{3}$ (dioxane) $)_{1.5}, \mathrm{UCl}_{4}$, $\mathrm{U}(\mathrm{O})\left[\mathrm{N}\left(\mathrm{SiMe}_{3}\right)_{2}\right]_{3}$, and $\mathrm{UO}_{2} \mathrm{Cl}_{2}(\mathrm{THF})_{3}$. The inflection point energies for $\mathbf{1}^{\mathbf{1 8 C 6}} \cdot 4 \mathrm{THF}$ and $\mathbf{1}^{\mathrm{THF}}$ are much higher than that of $\mathrm{UI}_{3}$ (dioxane) $)_{1.5}$ by 2.9 and $3.8 \mathrm{eV}$, respectively, but closer in range to that found for $\mathrm{UCl}_{4}(\Delta(\mathrm{eV})=+0.1$ $\left.\mathrm{eV}\left(\mathbf{1}^{\mathbf{1 8 C 6}} \cdot 4 \mathrm{THF}\right) ;+1.0 \mathrm{eV}\left(\mathbf{1}^{\mathbf{T H F}}\right)\right)$. However, $\mathbf{1}^{\text {THF }}$ is only $0.7 \mathrm{eV}$ lower than that found for pentavalent $\mathrm{U}(\mathrm{O})\left[\mathrm{N}\left(\mathrm{SiMe}_{3}\right)_{2}\right]_{3}$. Turning to the white line energies for further comparison, the peaks of $\mathbf{1}^{\mathbf{1 8 C 6}} \cdot 4 \mathrm{THF}$ and $\mathbf{1}^{\mathrm{THF}}$ exceed that of $\mathrm{UCl}_{4}$ by 1.1 and $2.4 \mathrm{eV}$, respectively, with the latter compound falling $0.6 \mathrm{eV}$ below the white line value of $\mathrm{U}(\mathrm{O})\left[\mathrm{N}\left(\mathrm{SiMe}_{3}\right)_{2}\right]_{3}$. 
Altogether, the data is generally consistent with a tetravalent oxidation state assignment for the uranium centers in $\mathbf{1}^{\mathbf{1 8 C} \mathbf{6}}$. $4 \mathrm{THF}$. The data also clearly indicates a more oxidized uranium species in the case of $\mathbf{1}^{\text {THF }}$, pinning the formal charge of its uranium atoms between U(IV)-U(V). To illustrate this, a plot of the inflection energies versus the oxidation states of the standards are provided in Figure $4 \mathrm{~b}$ containing a linear regression for the series. This analysis has been previously applied for the corroboration of oxidation state assignments in uranium coordination compounds. ${ }^{80}$ When plotting $\mathbf{1}^{\mathbf{1 8 C 6}}$. $4 \mathrm{THF}$ and $\mathbf{1}^{\mathrm{THF}}$, the respective calculated values for their metal oxidation states are found to be $\mathrm{U}^{+4.31}$ and $\mathrm{U}^{+4.76}$. The difference in the calculated charges is significant and provides a possible explanation for the observed disparity in their $\mu_{\text {eff }}$ plots (Figure 3). Namely, the more oxidized, ion-paired $\mathbf{1}^{\text {THF }}$ shows a lower overall $\mu_{\text {eff }}$ as compared to more electron rich $1^{18 C 6}$. 4 THF. Additionally, the g-value for $1^{\text {THF }}$ also exhibits less metal contribution. As such, the contact pairing of the potassium cations in $\mathbf{1}^{\text {THF }}$ play a sizable effect on the relative charge state of the uranium metal centers, despite the ion-pairing taking place beyond the immediate coordination sphere of uranium. A somewhat related phenomenon has been observed in the inverted sandwich complex $\left\{\mathrm{U}^{\mathrm{IV}}\left[\mathrm{OSi}\left(\mathrm{O}^{t} \mathrm{Bu}\right)_{3}\right]_{3}\right\}$ ${ }_{2}\left(\mu-\eta^{6}: \eta^{6}-\mathrm{C}_{7} \mathrm{H}_{8}\right)$ where addition of K[OTf] results in the cation-mediated disproportionation to U(IV)/U(IV) and $\mathrm{U}(\mathrm{IV}) / \mathrm{U}(\mathrm{V})$ complexes, a feat that does not occur upon treatment with non-coordinating cations such as $\left[\mathrm{NBu}_{4}\right]^{+} .{ }^{40}$ These observations signal that the electronic structure of uranium is highly sensitive to subtle perturbations within its ligand environment, especially when adding other interacting Lewis acid cations.

Furthermore, assuming formal U(IV) assignments for the uranium centers in $\mathbf{1}^{\mathbf{1 8 C} 6} \cdot 4 \mathrm{THF}$ and $\mathbf{1}^{\mathrm{THF}}$ yields a charge formulation of $\left(\mathrm{C}_{14} \mathrm{H}_{10}\right)^{2-}$ for each of the anthracene ligands. Nevertheless, each anthracene still adopts a distinctive coordination mode to uranium. In order to gain further insights into the electronic structure and the bonding interactions between uranium and the anthracenes, electronic structure analyses were performed.

Electronic Structure Analysis. Density functional theory (DFT) calculations (RI-PBE-D3/def2-TZVP, ${ }^{83-86}$ defTZVP for $\left.\mathrm{U}^{87-89}\right)$ were performed in the Turbomole program package ${ }^{90}$ to study the model systems $\left\{\left[\mathrm{U}\left(\eta^{6}-\right.\right.\right.$ $\left.\left.\left.\mathrm{C}_{14} \mathrm{H}_{10}\right)\left(\eta^{4}-\mathrm{C}_{14} \mathrm{H}_{10}\right)(\mu-\mathrm{OMe})\right]_{2}\right\}^{2-}\left(\mathbf{1}^{*}\right)$ and $\left\{\mathrm{K}\left[\mathrm{U}\left(\eta^{6}-\mathrm{C}_{14} \mathrm{H}_{10}\right)\left(\eta^{4}-\mathrm{C}_{14} \mathrm{H}_{10}\right)(\mu-\mathrm{OMe})\right]\right\}_{2}\left(\mathbf{1}-\mathbf{K}^{*}\right)$ (see SI for full computational details). Both $\mathbf{1}^{*}$ and $\mathbf{1 - \mathbf { K } ^ { * }}$ were optimized in the triplet, quintet, and septet spin states and confirmed as minima by harmonic vibrational analysis. The optimized structures for all three spin states were compared to those obtained from the X-ray determined structures by comparing U-C bond distances as summarized in Table 1 and detailed in Tables S4 and S5. The root-mean-square deviation (RMSD) for each DFT optimized structure was also calculated. The geometry from the ground state quintet is in closest agreement with both experimental structures (Figures S2 and S6); however, comparing the RMSD values for all three spin states suggests that all of the calculated geometries are in satisfactory agreement with the experimental data. For $\mathbf{1}^{*}$, the RMSD for the triplet, quintet, and septet states are $0.311,0.326$, and $0.331 \AA$, respectively. Similarly, the RMSD values for the same states are 
$0.348,0.320$, and $0.360 \AA$ for $\mathbf{1}-\mathbf{K}^{*}$. With respect to the relative calculated energies, the quintet ground state is favored for both $\mathbf{1}^{*}$ and 1-K* (Table S3, Figure S18) as both the triplet and septet states lie approximately 7 $\mathrm{kcal} / \mathrm{mol}$ higher in comparison. The electronic structures of $\mathbf{1}^{*}$ and $\mathbf{1 - K} *$ in the quintet state are comparable; though, the calculated average U-C bond distances of $\mathbf{1 - K ^ { * }}$ are found to be slightly shorter than for $\mathbf{1}^{*}$ (Table 1 ). In the quintet state, each uranium is in a $5 f^{2}$ electronic configuration, supporting the $\mathrm{U}(\mathrm{IV})$ assignments determined from the XANES data (Figure 4) and the curvature of the temperature dependent $\mu_{\text {eff }}$ plots (Figure 3).

To provide insight into the nature of the U-C bonds, bond orders were calculated using the Amsterdam Density Functional program package $(\mathrm{ADF})^{91}$ at the PBE/TZP level of theory. Generally, a Mayer bond order of 1, 2, or 3 corresponds to a single, double, or triple bond between two atoms, respectively, although deviations from integer values are expected for highly polarized bonds. ${ }^{92}$ The average Mayer bond order of the U-C $\left(\eta^{4}\right)$ bonds in $\mathbf{1}^{*}$ and 1 $\mathbf{K}^{*}$ are 0.40 and 0.33 , respectively (Table S7 and S9). This indicates slightly greater orbital overlap between the $\eta^{4}-\mathrm{C}_{14} \mathrm{H}_{10}$ ligands and the uranium atoms in $\mathbf{1} *$ versus that of $\mathbf{1}-\mathbf{K}^{*}$. Though, no significant differences are observed when determining the total bond orders through Gopinathan-Jug or Nalewajski-Mrozek methods (Table S7 and S9). In comparison, the Mayer bond orders for the $\mathrm{U}-\mathrm{C}\left(\eta^{6}\right)$ interactions are unaffected by the presence of the potassium ion and found to range from 0.22 to 0.50 (avg. 0.31) for $\mathbf{1}^{*}$ (Table S7) and 0.23 to 0.52 (avg. 0.32) for 1K* (Table S9). The nature of the U-C $\left(\eta^{4}\right)$ and $\mathrm{U}-\mathrm{C}\left(\eta^{6}\right)$ interactions was also studied by dividing the molecule into two fragments along the $\mathrm{U}$-anthracene bonds of each ligand type in order to perform energy decomposition analysis (EDA) (Table S19). The bond energy for $1 *$ is -150.37 and $-154.86 \mathrm{kcal} / \mathrm{mol}$ for the $\eta^{4}$ - and $\eta^{6}$-anthracene ligands, respectively. Furthermore, orbital interactions contribute $49.4 \%$ and $50.7 \%$ to the attractive energy. Both values indicate a slightly stronger interaction with the $\eta^{6}$-anthracene ligand.

Quantum theory of atoms in molecules (QTAIM) analyses for 1* and 1-K* identified two bond critical points (BCPs) between the uranium centers and the $\eta^{6}$-rings and three bond critical points for the $\eta^{4}$-anthracene ligands. At all BCPs, the total electronic energy density, E(r), is negative $\left(\mathbf{1}^{*}:-0.0077--0.0116 ; \mathbf{1}-\mathbf{K}^{*}:-0.0075--0.0125\right)$, and the Laplacian of the density, $\nabla^{2}(\rho)$, is positive $\left(1^{*}: 0.0825-0.1149 ; \mathbf{1}-\mathbf{K}^{*}: 0.0800-0.1261\right)$ (Table S6). In addition, the electron density values, $\rho$, are small $\left(1^{*}: 0.0471-0.0554 ; \mathbf{1}-\mathbf{K}^{*}: 0.0490-0.0572\right)$, altogether indicating U-C dative bonding where the interactions can be described as primarily ionic or exhibiting strongly polarized bonding character. ${ }^{93}$

The DFT frontier molecular orbitals of $\mathbf{1}^{*}$ and $\mathbf{1 - \mathbf { K } ^ { * }}$ are illustrated in Figure 5 and show that the U-C $\left(\eta^{6}\right)$ interactions for both $\mathbf{1}^{*}$ and $\mathbf{1 - \mathbf { K } ^ { * }}$, as defined by the crystallographically determined uranium-carbon bond lengths for $\mathbf{1}^{\mathbf{1 8 C 6}} \cdot 4 \mathrm{THF}$ and $\mathbf{1}^{\mathrm{THF}}$ (vide supra), are nominally hexahapto. The electronic structure shows the coordination mode of this anthracene to be better described as bidentate with the strongest interactions occurring through $\pi$-bonding at the bridgehead carbon atoms with negligible contributions from the remaining carbons of the central ring, consistent

Table 1. Selected metal-ligand distances from RI-PBE-D3/def2-TZVP, def-TZVP optimized geometries for the triplet, quintet, and septet spin states of $\mathbf{1}^{*}$ and $\mathbf{1 - K ^ { * }}$. Values are averaged. Distances are in angstrom $(\AA)$.

\begin{tabular}{lllllll}
\hline \multirow{2}{*}{ Compounds } & Spin & $\mathrm{U} 1-\mathrm{C}\left(\boldsymbol{\eta}^{6}\right)$ & $\mathrm{U} 1-\mathrm{C}\left(\boldsymbol{\eta}^{4}\right)$ & $\mathrm{U} 2-\mathrm{C}\left(\boldsymbol{\eta}^{6}\right)$ & $\mathrm{U} 2-\mathrm{C}\left(\boldsymbol{\eta}^{4}\right)$ & $\mathrm{U}-\mathrm{O}$ \\
\hline $1^{*}$ & triplet & 2.746 & 2.659 & 2.723 & 2.639 & 2.331 \\
& quintet & 2.743 & 2.659 & 2.748 & 2.658 & 2.333 \\
& septet & 2.762 & 2.675 & 2.748 & 2.732 & 2.323 \\
& Exp. & 2.713 & 2.658 & 2.713 & 2.658 & 2.328 \\
\hline $1-\mathrm{K}^{*}$ & triplet & 2.712 & 2.625 & 2.734 & 2.642 & 2.323 \\
& quintet & 2.734 & 2.641 & 2.733 & 2.642 & 2.326 \\
& septet & 2.790 & 2.649 & 2.790 & 2.649 & 2.313 \\
& Exp. & 2.700 & 2.674 & 2.700 & 2.674 & 2.336 \\
\hline
\end{tabular}




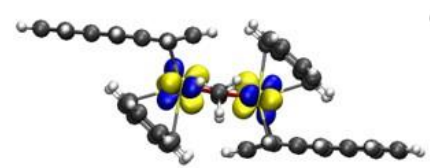

SOMO-3

$\mathrm{U}=89.4 \%, \mathrm{C}=6.4 \%$

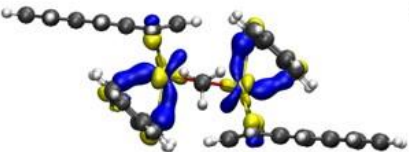

HOMO-7

$\mathrm{U}=26.3 \%, \mathrm{C}=38.8 \%$

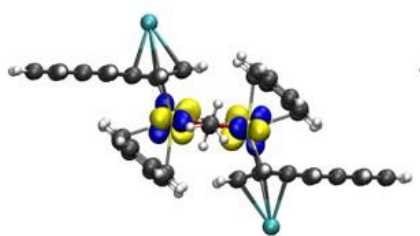

SOMO-3

$\mathrm{U}=89.4 \%, \mathrm{C}=6.0 \%$

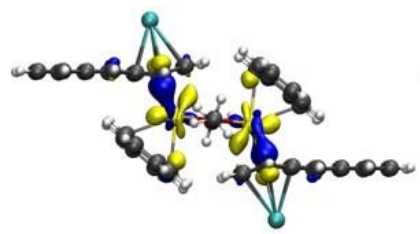

HOMO-7

$\mathrm{U}=22.5 \%, \mathrm{C}=38.9 \%$

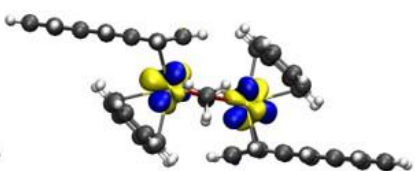

SOMO-2

$\mathrm{U}=80.4 \%, \mathrm{C}=10.5 \%$

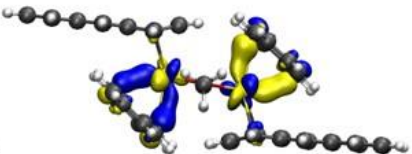

HOMO-6

$\mathrm{U}=26.8 \%, \mathrm{C}=38.9 \%$

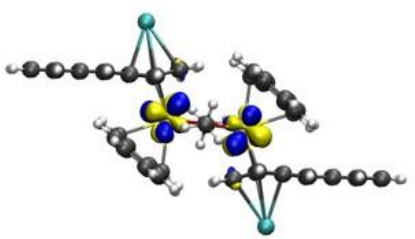

SOMO-2

$\mathrm{U}=75.7 \% . \mathrm{C}=12.4 \%$

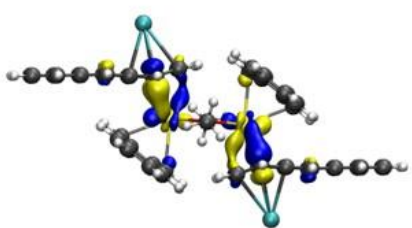

HOMO-6

$\mathrm{U}=23.3 \%, \mathrm{C}=38.2 \%$

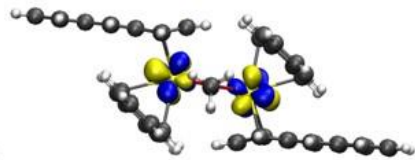

SOMO-1

$\mathrm{U}=87.6 \%, \mathrm{C}=6.0 \%$

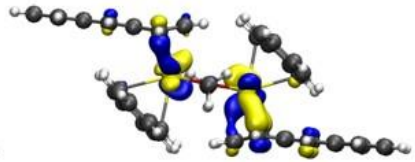

HOMO-5

$\mathrm{U}=27.3 \%, \mathrm{C}=32.5 \%$

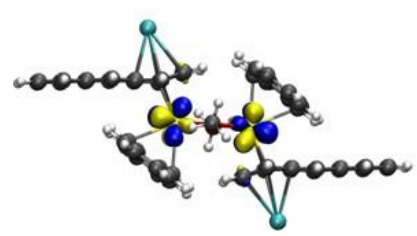

SOMO-1

$\mathrm{U}=91.2 \%, \mathrm{C}=4.1 \%$

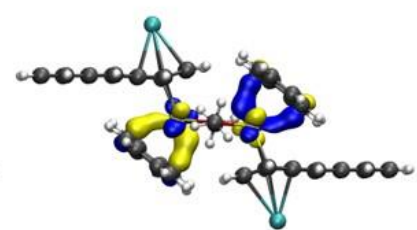

HOMO-5

$\mathrm{U}=31.2 \%, \mathrm{C}=35.0 \%$

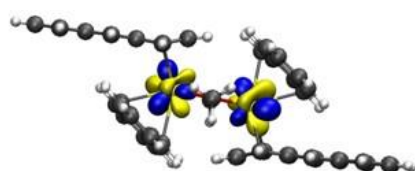

SOMO

$\mathrm{U}=80 \%, \mathrm{C}=10.0 \%$

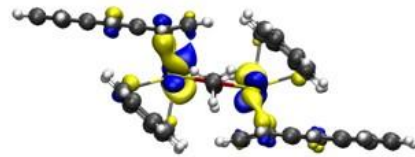

HOMO-4

$\mathrm{U}=27.3 \%, \mathrm{C}=32.8 \%$

Figure 5. DFT frontier molecular orbitals (MOs) of $\mathbf{1} *$ (top) and $\mathbf{1 - K}$ (bottom). Only $\alpha$-spin orbitals are shown. The Hirshfeld atomic contributions to the MOs are given (only contributions from the carbon atoms coordinated to the uranium are reported). An iso value of 0.04 a.u. was used. $\mathrm{U}$ in blue, $\mathrm{C}$ in grey, $\mathrm{O}$ in red, and $\mathrm{H}$ in white.

with the findings of the QTAIM BCPs. With respect to the $\mathrm{U}-\mathrm{C}\left(\eta^{4}\right)$ fragments of $\mathbf{1}^{*}$ and $\mathbf{1 - \mathbf { K } ^ { * }}$, orbital overlap is observed with all four carbon atoms, albeit more so at the $\mathrm{C} 1 / \mathrm{C} 4$ fold atoms.

The DFT-calculated frontier molecular orbitals of $\mathbf{1}^{*}$ and $\mathbf{1 - K ^ { * }}$ in Figure 5 are displayed with the total percent electronic contribution of the uranium centers and sum of the carbon orbitals involved in the bonds. In both cases, the singly occupied molecular orbitals (SOMOs), SOMO to SOMO-3, are predominately $5 f$ in character with HOMO-4 through HOMO-7 defining the U-C interactions. In 1*, HOMO-6 and HOMO-7 are also primarily defined by the orbitals of the $\mathrm{U}-\mathrm{C}\left(\eta^{6}\right)$ interactions. Yet, in $\mathbf{1 - K ^ { * }}$, the corresponding frontier orbitals are comprised by the $\mathrm{U}-\mathrm{C}\left(\eta^{4}\right)$ bonding compositions. In either case, the bonds appear highly polarized with the contributions from the uranium atoms approaching $25 \%$ and those from the carbon atoms nearing $40 \%$.

The Charge Model 5 (CM5) atomic charges were found for each system (Table S11). The average charge of each uranium ion is +1.0 for both $1^{*}$ and $\mathbf{1 - K ^ { * }}$. On the other hand, the ion pairing has a significant effect on the relative charges of the arenide anions. The combined partial charges for the carbon atoms for each of the $\eta^{4}-\mathrm{C}_{14} \mathrm{H}_{10}$ and $\eta^{6}-\mathrm{C}_{14} \mathrm{H}_{10}$ ligands in $\mathbf{1}^{*}$ are -0.87 and -0.77 , respectively. This decreases in $\mathbf{1 - K} *$ to -0.55 for the $\eta^{6}-\mathrm{C}_{14} \mathrm{H}_{10}$ ligands but increases to -0.95 for the $\eta^{4}-\mathrm{C}_{14} \mathrm{H}_{10}$ anthracenides, where the presence of the coordinated potassium cations allows for greater charge accumulation in the latter. Note that in both cases, the relative charge on the $\eta^{4}$ $\mathrm{C}_{14} \mathrm{H}_{10}$ ligands exceed those of the $\eta^{6}-\mathrm{C}_{14} \mathrm{H}_{10}$ arenides.

Since uranium complexes often exhibit multiconfigurational electronic structures not adequately treated with DFT, the electronic structure was studied by the complete active space self-consistent field (CASSCF) method 


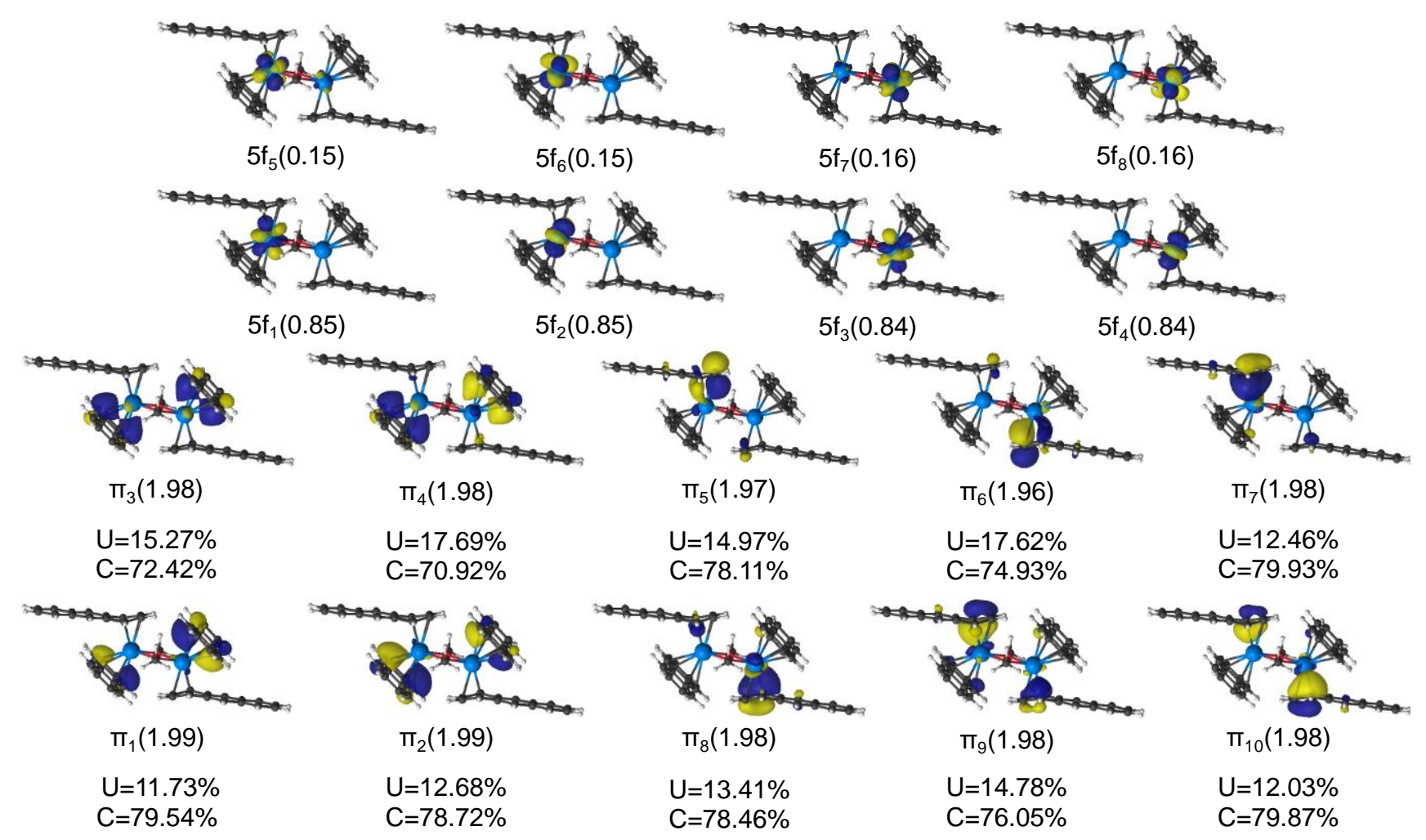

Figure 6. RASSCF natural orbitals and occupation numbers are shown for the quintet state of $1 *$. The $\pi$-orbitals are in RAS1 and the $5 f$ orbitals are in RAS2. RAS3 is not plotted (see Figure S28). Percent contributions of uranium to the RAS1 orbitals are included. An isovalue of 0.04 a.u. was used. $\mathrm{U}$ in blue, $\mathrm{C}$ in grey, $\mathrm{O}$ in red, and $\mathrm{H}$ in white.

along with second-order energy corrections (CASPT2) ${ }^{94-95}$ for $\mathbf{1}^{*}$. In CASPT2, including only the $5 f$-orbitals and their corresponding electrons in the active space $(4 e, 14 o)$, the singlet, triplet, and quintet states are effectively degenerate lying within $0.3 \mathrm{kcal} / \mathrm{mol}$ of one another. As such, we cannot assign a single spin state as the ground state. We expect that the true ground state is a spin-orbit coupled state with contributions from the singlet, triplet, and quintet spin-free states.

Since the DFT shows covalent interactions between the uranium centers and the arenide ligands, the bonding in dimer $1 *$ was also studied with the restricted active space self-consistent field (RASSCF) method with corrections from second-order perturbation theory (RASPT2), ${ }^{96-97}$ allowing for larger active spaces to be studied than in CASSCF. All CASPT2 and RASPT2 calculations were performed in Open Molcas. ${ }^{98}$

The active space would ideally include all of the molecular orbitals that are linear combinations of uranium $5 f$ orbitals and orbitals that include bonding or antibonding interactions between uranium and the arenide ligands. While there are total of $145 f$-orbitals in $1^{*}$, they are not all occupied due to crystal field effects. Therefore, after the aforementioned $(4 e, 14 o)$ active space was used, it was determined that only 8 of these orbitals need be included, $(4 e, 8 o)$ (Figures $\mathrm{S} 20$ to S25). By inspection of the $(4 e, 8 o)$ orbitals, 10 pairs of $\pi$-bonding and anti-bonding orbitals were also identified. This surpasses the number of orbitals one can include in CASSCF; therefore, the RASSCF method was used to restrict excitations in a subset of the active space.

Specifically, RASSCF/RASPT2 calculations were performed including the $10 \pi$-orbitals in the so-called RAS1 space, eight $5 f$-orbitals in the RAS2 space, and $10 \pi^{*}$-orbitals in the RAS3 space. All excitations are allowed within RAS2 but only configurations with up to two holes are allowed in RAS1 and up to two electrons in RAS3, denoted $(24 e, 2 h, 2 e ; 10 o, 8 o, 10 o)$ using the notation of Sauri et al. ${ }^{97}$ The calculations yield occupation numbers for the $\pi$ orbitals in RAS1 that are 1.96 or higher, consistent with a doubly occupied orbital. Likewise, those in RAS3 have occupation numbers of 0.04 or less, signaling empty orbitals. Based on the RASSCF results, the active space can be further reduced to $(8 e, 12 o)$, the results of which remain similar to RASSCF (Table S12-S13). 
RASPT2 predicts that the singlet, triplet, and quintet states are within $0.3 \mathrm{kcal} / \mathrm{mol}$ of one another. Note that DFT cannot describe the multiconfigurational singlet and triplet states in which the $5 f$-electrons are weakly coupled with one another; however, both CASPT2 and RASPT2 suggest interpreting the DFT high-spin quintet state to understand the uranium-carbon interactions is reasonable.

The RASSCF natural orbitals for the quintet state are included in Figure 6, although the singlet and triplet orbitals are qualitatively the same (Figures S29-S30). In the RAS1 space, the total uranium orbital contribution to the U-C $\pi$-interactions across the $\mathrm{U}-\mathrm{C}\left(\eta^{6}\right)$ and $\mathrm{U}-\mathrm{C}\left(\eta^{4}\right)$ bonds range from $11.7 \%$ to $17.7 \%$ in $1^{*}$. The average uranium contribution between the U-C $\left(\eta^{6}\right)$ (avg. 14.3\%) and $\mathrm{U}-\mathrm{C}\left(\eta^{4}\right)$ bonds (avg. 14.2\%) are comparable. Of particular note, in contrast to the DFT orbital picture, the $5 f$-orbitals play a minimal to negligible role in the U-C bonding of 1* (Figure 6). The average contributions of the uranium orbitals to the bonding scheme in the quintet state is $7.3 \pm$ $0.6 \%(6 d), 2.5 \pm 0.4 \%(6 p), 1.5 \pm 0.4 \%(5 f)$, and $1.4 \pm 1.4 \%(7 s)$. Accordingly, the uranium $6 d$-orbitals are the dominant contributors accompanied by some semi-core $6 p$-orbital participation.

Noticeably absent are metal-arene bonding interactions that can be described as $\delta$-bonds, which is a significant departure from the bonding schemes determined for actinide inverted sandwich complexes. ${ }^{32}$ For example, CASSCF analyses on $\left(\mu-\eta^{6}: \eta^{6}-\mathrm{C}_{7} \mathrm{H}_{8}\right) \mathrm{U}_{2}\left[\mathrm{~N}\left({ }^{t} \mathrm{Bu}\right)\left(3,5-\mathrm{C}_{6} \mathrm{H}_{3} \mathrm{Me}_{2}\right)\right]_{4}{ }^{37}$ and $[\mathrm{U}(\mathrm{BIPM})]_{6}(\mu-\mathrm{I})_{3}\left(\mu-\eta^{6}: \eta^{6}-\mathrm{C}_{6} \mathrm{H}_{6}\right)_{3}(\mathrm{BIPM}=$ $\left.\left(\mathrm{C}\left(\mathrm{PH}_{2} \mathrm{NH}\right)_{2}\right)^{2-}\right)^{38}$ both show significant $\delta$-bonding overlap between the $\pi^{*}$-orbitals of the arenes and filled $5 f$-orbitals. The sandwiched rings in these compounds are formally tetraanions and bound by two metals, which together limits structural distortions and favors the $\delta$-bonding. In our case, formal two-electron reduction of each of the anthracene ligands leads to ring folding that greatly diminishes the possibility for uranium-anthracene $\delta$-bonding.

Lastly, while the EPR spectral results are not consistent with a purely closed shell anthracene ligand in the cases of $\mathbf{1}^{18 \mathrm{C} 6} .4 \mathrm{THF}$ and $\mathbf{1}^{\mathrm{THF}}$, DFT, CASSCF, and RASSCF calculations predict that all of the unpaired spin density in the gas phase $\mathbf{1}^{*}$ and $\mathbf{1 - K ^ { * }}$ structures is metal centered. This follows the SQUID magnetometry and XANES spectral analysis for $\mathbf{1}^{\mathbf{1 8 C 6}}$. $4 \mathrm{THF}$ and $\mathbf{1}^{\mathrm{THF}}$ that generally support a formal oxidation state of U(IV) for both complexes. Our electronic structure analysis does not include thermal contributions, and we have not systematically explored low-lying electronic states or the effect of crystal packing that could be contributing to the observed EPR spectra.

\section{Summary}

Metal-arene sandwich complexes are an important class of molecules that have been instrumental in understanding the electronic properties and orbital characteristics of the $d$-block series while providing access to important arene-functionalization chemistry. Extension of these systems to the $f$-elements has been limited to only a handful of lanthanide-arene sandwich complexes, mainly synthesized by electron beam vaporization techniques, ${ }^{12-14}$ and the poorly characterized, heteroleptic thorium species $\left\{\left[\mathrm{O}-2,4-{ }^{t} \mathrm{Bu}_{2}-\mathrm{C}_{6} \mathrm{H}_{2}\left(\mathrm{CH}_{2}\right)\right]_{2} \mathrm{Th}\left(\eta^{4}-\mathrm{C}_{10} \mathrm{H}_{8}\right)_{2}\right\}[\mathrm{K}(18$-crown6) $]_{2}{ }^{31}$ Utilizing Chatt reaction protocols popularized by Ellis, ${ }^{10}$ we have shown that the reaction of $\left[\mathrm{UI}_{2}\left(\mathrm{THF}_{3}(\mu-\right.\right.$

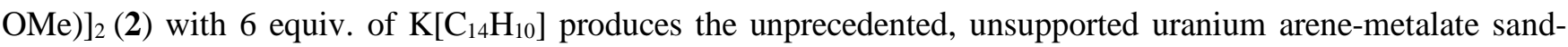
wiches $\left[\mathrm{K}(18 \text {-crown-6)(THF })_{2}\right]_{2}\left[\mathrm{U}\left(\eta^{6}-\mathrm{C}_{14} \mathrm{H}_{10}\right)\left(\eta^{4}-\mathrm{C}_{14} \mathrm{H}_{10}\right)(\mu-\mathrm{OMe})\right]_{2} \quad\left(\mathbf{1}^{\mathbf{1 8 C 6}}\right)$ and $\left\{\left[\mathrm{K}(\mathrm{THF})_{3}\right]\left[\mathrm{U}\left(\eta^{6}-\mathrm{C}_{14} \mathrm{H}_{10}\right)\left(\eta^{4}-\right.\right.\right.$ $\left.\left.\left.\mathrm{C}_{14} \mathrm{H}_{10}\right)(\mu-\mathrm{OMe})\right]\right\}_{2}\left(\mathbf{1}^{\mathrm{THF}}\right)$ in the presence and absence of 18 -crown- 6 , respectively.

As shown through X-ray diffractometry, the arene ligands in both complexes display notable ring fold angles, indicative of formal reduction and partial dearomatization of the anthracene moieties. While the cores of both $\mathbf{1}^{\mathbf{1 8 C 6}}$ and $\mathbf{1}^{\text {THF }}$ comprise of a dimeric $\left\{\left[\mathrm{U}\left(\eta^{6}-\mathrm{C}_{14} \mathrm{H}_{10}\right)\left(\eta^{4}-\mathrm{C}_{14} \mathrm{H}_{10}\right)(\mu-\mathrm{OMe})\right]_{2}\right\}^{2-}$ unit, the two systems are distinguished by close-contact arene-pairing of the potassium cation that occurs in $\mathbf{1}^{\mathrm{THF}}$ but is missing in $\mathbf{1}^{18 \mathrm{C} 6} \cdot 4 \mathrm{THF}$, due to polyether sequestration of the potassium cations in the latter. Despite their structural similarity, XANES analysis and magnetic characterization of $\mathbf{1}^{\mathbf{1 8 C} 6}$. 4THF and $\mathbf{1}^{\mathrm{THF}}$ show appreciable differences in their electronic and magnetic properties. For instance, the effective magnetic moment of $\mathbf{1}^{\mathbf{1 8 C 6}} \cdot 4 \mathrm{THF}\left(\mu_{\mathrm{eff}}=4.40 \mu_{\mathrm{B}}\right)$ is significantly higher than $\mathbf{1}^{\text {THF }}\left(\mu_{\mathrm{eff}}=3.74 \mu_{\mathrm{B}}\right)$ at $300 \mathrm{~K}$, though both complexes show a temperature dependent $\mu_{\mathrm{eff}}$ response in line with U(IV) centers (Figure 3). The XANES spectra shows an obvious difference in the level of oxidation between the uranium atoms of $\mathbf{1}^{\mathbf{1 8 C 6}} \cdot 4 \mathrm{THF}$ and $\mathbf{1}^{\mathrm{THF}}$ (Figure 4a), with the linear regression fitting of the edge energies yielding formal charges of $U^{+4.31}$ for $\mathbf{1}^{18 C 6} \cdot 4 \mathrm{THF}$ and $\mathrm{U}^{+4.76}$ for $\mathbf{1}^{\mathrm{THF}}$ (Figure $4 \mathrm{~b}$ ). Together, the data clearly signals that the 
close-contact ion pairing of the potassium cations has a direct effect on the electronic structure of the actinide centers and the oxidation states of the metal centers. We attribute this to enhanced bond polarization effects enabled by the coordinated, Lewis acidic potassium cations, which leads to greater localized charge character at the $\eta^{4}$ anthracene ligands.

Electronic structure analysis of the isolated diuranium complexes $\mathbf{1}^{*}$ and $\mathbf{1 - \mathbf { K } ^ { * }}$ by DFT calculations and $\mathbf{1}^{*}$ by RASPT2 methods indicates that the uranium-carbon bonding is highly polarized with modest orbital contributions from the uranium atoms. DFT analysis of 1-K* also substantiates increased charge polarization at the potassiumbound anthracenes. In stark contrast to thorium and uranium inverted sandwich complexes, $\delta$-bonding between

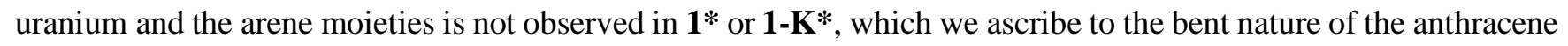
ligands that prevents metal-arene $\delta$-symmetry orbital overlap. Instead, the metal-ligand bonding is best described as comprising of $\pi$-type bonds. Interestingly, RASSCF calculations reveal little participation of the $5 f$-orbitals to the uranium-carbon interactions, with the $6 d$-orbitals providing the greatest contributions.

Efforts are currently underway to modify the reaction conditions and choice of arene ligands in order to obtain homoleptic uranium-arene sandwich complexes to further probe the electronic and chemical properties of this unique class of molecules.

\section{ACKNOWLEDGMENTS}

We are grateful to the Welch Foundation (AH-1922-20200401; S.F.) and the NSF (DMR-1827745; CHE-1827875) for financial support of this work. S.F. is an Alfred P. Sloan Foundation research fellow and is thankful for their support. MRCAT operations are supported by the Department of Energy and the MRCAT member institutions. This research used resources of the Advanced Photon Source, a U.S. Department of Energy (DOE) Office of Science User Facility operated for the DOE Office of Science by Argonne National Laboratory under Contract No. DE-AC02-06CH11357. Computations supporting this project were performed on High Performance Computing systems at the University of South Dakota, funded by NSF Award OAC-1626516. B.V. would like to thank the University of South Dakota for start-up funds. B.V., P.M., and R.B. acknowledge that the land their research was performed on is the original homelands of the Dakota, Lakota, and Nakota tribal nations. K.L.M.H. and M.M. are grateful for the support and funds from the University of Ottawa, the Natural Sciences and Engineering Research Council of Canada, and the Canadian Foundation for Innovation

\section{REFERENCES}

1. Seyferth, D., Bis(benzene)chromium. 2. Its Discovery by E. O. Fischer and W. Hafner and Subsequent Work by the Research Groups of E. O. Fischer, H. H. Zeiss, F. Hein, C. Elschenbroich, and Others. Organometallics 2002, 21, 2800-2820.

2. $\quad$ Astruc, D., Why is Ferrocene so Exceptional? Eur. J. Inorg. Chem. 2017, 6-29.

3. Werner, H., At Least 60 Years of Ferrocene: The Discovery and Rediscovery of the Sandwich Complexes. Angew. Chem. Int. Ed. 2012, 51, 6052-6058.

4. Osborne, J. H.; Trogler, W. C.; Morand, P. D.; Francis, C. G., Electronic-Structures of Bis(Benzene)Chromium and the $C_{2 \mathrm{~h}}$ and $C_{2 \mathrm{v}}$ Isomers of Bis(Naphthalene)Chromium. Organometallics 1987, 6, 94-100.

5. Weber, J.; Kundig, E. P.; Goursot, A.; Penigault, E., The Electronic-Structures of Bis $\left(\eta^{6}\right.$-Benzene)- and $\operatorname{Bis}\left(\eta^{6}\right.$-Naphthalene)Chromium(0). Can. J. Chem. 1985, 63, 1734-1740.

6. Rayón, V. M.; Frenking, G., Bis(benzene)chromium is a $\delta$-Bonded Molecule and Ferrocene is a $\pi$-Bonded Molecule. Organometallics 2003, 22, 3304-3308. 
7. Sahnoun, R.; Mijoule, C., Density Functional Study of Metal-Arene Compounds: Mono(benzene)chromium, Bis(benzene)chromium and Their Cations. J. Phys. Chem. A 2001, 105, 6176-6181.

8. Rosillo, M.; Domínguez, G.; Pérez-Castells, J., Chromium arene complexes in organic synthesis. Chem. Soc. Rev. 2007, 36, 1589-1604.

9. Pampaloni, G., Aromatic hydrocarbons as ligands. Recent advances in the synthesis, the reactivity and the applications of bis $\left(\eta^{6}\right.$-arene) complexes. Coord. Chem. Rev. 2010, 254, 402-419.

10. Ellis, J. E., The Chatt reaction: conventional routes to homoleptic arenemetalates of d-block elements. Dalton Trans. 2019, 48, 9538-9563.

11. The term "arene" is here defined as any neutral monocyclic or polycyclic hydrocarbon that possesses aromatic character prior to metal ligation and is distinguished from other carbocyclic ligands, such as $\mathrm{Cp}^{-}$, which only acheive aromaticity upon chemical transformation or reduction of their parent hydrocarbon.

12. Brennan, J. G.; Cloke, F. G. N.; Sameh, A. A.; Zalkin, A., Synthesis of bis $\left(\eta^{6}-1,3,5\right.$-tri-t-butylbenzene) sandwich complexes of yttrium(0) and gadolinium( $(0)$; the X-ray crystal structure of the first authentic lanthanide( $(0)$ complex, $\left[\mathrm{Gd}\left(\eta^{6}-\mathrm{Bu}_{3}{ }_{3} \mathrm{C}_{6} \mathrm{H}_{3}\right)_{2}\right]$. J. Chem. Soc., Chem. Comm. 1987, 1668-1669.

13. Anderson, D. M.; Cloke, F. G. N.; Cox, P. A.; Edelstein, N.; Green, J. C.; Pang, T.; Sameh, A. A.; Shalimoff, G., On the Stability and Bonding in Bis( $\eta$-Arene)Lanthanide Complexes. J. Chem. Soc. Chem. Comm. 1989, 53-55.

14. Cloke, F. G. N., Zero Oxidation-State Compounds of Scandium, Yttrium, and the Lanthanides. Chem. Soc. Rev. 1993, 22, 17-24.

15. Hong, G. Y.; Schautz, F.; Dolg, M., Ab initio study of metal-ring bonding in the bis $\left(\eta^{6}\right.$-benzene)lanthanide and -actinide complexes $\mathrm{M}\left(\mathrm{C}_{6} \mathrm{H}_{6}\right)_{2}(\mathrm{M}=\mathrm{La}, \mathrm{Ce}, \mathrm{Nd}, \mathrm{Gd}, \mathrm{Tb}, \mathrm{Lu}, \mathrm{Th}, \mathrm{U})$. J. Am. Chem. Soc. 1999, 121, 1502-1512.

16. Dolg, M., Combined Pseudopotential and Density Functional Study of Bis- $\eta^{6}$-benzene d and f Element Complexes. J. Chem. Inf. Model. 2001, 41, 18-21.

17. King, W. A.; DiBella, S.; Lanza, G.; Khan, K.; Duncalf, D. J.; Cloke, F. G. N.; Fragala, I. L.; Marks, T. J., Metal-ligand bonding and bonding energetics in zerovalent lanthanide, group 3, group 4, and group 6 bis(arene) sandwich complexes. A combined solution thermochemical and ab initio quantum chemical investigation. J. Am. Chem. Soc. 1996, 118, 627-635.

18. Kelly, R. P.; Maron, L.; Scopelliti, R.; Mazzanti, M., Reduction of a Cerium(III) Siloxide Complex to Afford a Quadruple-Decker Arene-Bridged Cerium(II) Sandwich. Angew. Chem. Int. Ed. 2017, 56, 15663-15666.

19. Minasian, S. G.; Keith, J. M.; Batista, E. R.; Boland, K. S.; Clark, D. L.; Kozimor, S. A.; Martin, R. L.; Shuh, D. K.; Tyliszczak, T., New evidence for $5 f$ covalency in actinocenes determined from carbon K-edge XAS and electronic structure theory. Chem. Sci. 2014, 5, 351-359.

20. Kelley, M. P.; Popov, I. A.; Jung, J.; Batista, E. R.; Yang, P., delta and phi back-donation in An(IV) metallacycles. Nat. Commun. 2020, 11.

21. Neidig, M. L.; Clark, D. L.; Martin, R. L., Covalency in f-element complexes. Coord. Chem. Rev. 2013, 257, 394-406. 
22. Yin, W. W.; Marshall, A. G.; Marcalo, J.; Dematos, A. P., Gas-Phase Synthesis and Ft/Icr Mass-Spectrometric Characterization of Sandwich Complexes of Sc+, Y+, and Lanthanide Ions with 1,3,5-Tri-Tert-Butylbenzene. J. Am. Chem. Soc. 1994, 116, 8666-8672.

23. Cesari, M.; Pedretti, U.; Zazzetta, Z.; Lugli, g.; Marconi, W., Synthesis and structure of a $\pi$-arene complex of uranium(III) - aluminum chloride. Inorg. Chim. Acta 1971, 5, 439-444.

24. Cotton, F. A.; Schwotzer, W., Preparation and structure of $\left[\mathrm{U}_{2}\left(\mathrm{C}_{6} \mathrm{Me}_{6}\right)_{2} \mathrm{Cl}_{7}\right]^{+}$, the first uranium(IV) complex with a neutral arene in $\eta^{6}$-coordination. Organometallics 1985, 4, 942-943.

25. Campbell, G. C.; Cotton, F. A.; Haw, J. F.; Schwotzer, W., Syntheses, Structures, and Solid-State C-13 NMR of two $\eta^{6}$-Arene Uranium(IV) Complexes, $\left[\mathrm{U}\left(\mathrm{C}_{6} \mathrm{Me}_{6}\right) \mathrm{Cl}_{2}(\mu-\mathrm{Cl})_{3} \mu \mathrm{Cl}_{2}\left(\mathrm{C}_{6} \mathrm{Me}_{6}\right)\right] \mathrm{AlCl}_{4}$ and $\mathrm{U}\left(\mathrm{C}_{6} \mathrm{Me}_{6}\right) \mathrm{Cl}_{2}(\mu-$ $\mathrm{Cl})_{3} \mu \mathrm{Cl}_{2}(\mu-\mathrm{Cl})_{3} \mu \mathrm{Cl}_{2}\left(\mathrm{C}_{6} \mathrm{Me}_{6}\right)$. Organometallics 1986, 5, 274-279.

26. Cotton, F. A.; Schwotzer, W.; Simpson, C. Q., $\left[\mathrm{U}_{3}\left(\mu_{3}-\mathrm{Cl}\right)_{2}(\mu-\mathrm{Cl})_{3}\left(\mu-\eta^{2}-\mathrm{AlCl}_{4}\right)_{3}\left(\eta^{6}-\mathrm{C}_{6} \mathrm{Me}_{6}\right)_{3}\right]\left[\mathrm{AlCl}_{4}\right]-$ a Trinuclear Arene Complex of U(III). Angew. Chem. Int. Edit. 1986, 25, 637-639.

27. Cotton, F. A.; Schwotzer, W., Syntheses and Structural Comparison of the $\eta$-6-Arene Complexes $\mathrm{Sm}\left(\mathrm{C}_{6} \mathrm{Me}_{6}\right)\left(\mathrm{AlCl}_{4}\right)_{3}$ and $\mathrm{U}\left(\mathrm{C}_{6} \mathrm{Me}_{6}\right)\left(\mathrm{AlCl}_{4}\right)_{3}$. Organometallics 1987, 6, 1275-1280.

28. Baudry, D.; Bulot, E.; Charpin, P.; Ephritikhine, M.; Lance, M.; Nierlich, M.; Vigner, J., Arene Uranium Borohydrides - Synthesis and Crystal-Structure of $\left(\eta^{6}-\mathrm{C}_{6} \mathrm{Me}_{6}\right) \mathrm{U}\left(\mathrm{BH}_{4}\right)_{3}$. J. Organomet. Chem. 1989, 371, $155-162$.

29. Paprocki, V.; Hrobárik, P.; Harriman, K. L. M.; Luff, M. S.; Kupfer, T.; Kaupp, M.; Murugesu, M.; Braunschweig, H., Stable Actinide $\pi$ Complexes of a Neutral 1,4-Diborabenzene. Angew. Chem. Int. Ed. 2020, 59, 1310913115.

30. Korobkov, I.; Gambarotta, S.; Yap, G. P. A., The first thorium arene complex: A divalent synthon. Angew. Chem. Int. Ed. 2003, 42, 814-818.

31. Korobkov, I.; Gambarotta, S.; Yap, G. P. A., Amide from dinitrogen by in situ cleavage and partial hydrogenation promoted by a transient zero-valent thorium synthon. Angew. Chem. Int. Ed. 2003, 42, 4958-4961.

32. Liddle, S. T., Inverted sandwich arene complexes of uranium. Coord. Chem. Rev. 2015, 293-294, 211-227.

33. Murillo, J.; Fortier, S., Actinides: Pentavalent Organometallics. Evans, W. J. and Hanusa, T. P., Eds.; John Wiley \& Sons, Ltd. Encyclopedia of Inorganic and Bioinorganic Chemistry 2018.

34. Hayton, T. W.; Kaltsoyannis, N., Organometallic Actinide Complexes with Novel Oxidation States and Ligand Types. Gibson, J. K. and de Jong, W. A., Eds. John Wiley \& Sons, Ltd. Experimental and Theoretical Approaches to Actinide Chemistry 2018, 181-236.

35. Diaconescu, P. L.; Arnold, P. L.; Baker, T. A.; Mindiola, D. J.; Cummins, C. C., Arene-Bridged Diuranium Complexes: Inverted Sandwiches Supported by $\delta$ Backbonding. J. Am. Chem. Soc. 2000, 122, 6108-6109.

36. Diaconescu, P. L.; Cummins, C. C., Diuranium Inverted Sandwiches Involving Naphthalene and Cyclooctatetraene. J. Am. Chem. Soc. 2002, 124, 7660-7661.

37. Vlaisayljevich, B.; Diaconescu, P. L.; Lukens, W. L.; Gagliardi, L.; Cummins, C. C., Investigations of the Electronic Structure of Arene-Bridged Diuranium Complexes. Organometallics 2013, 32, 1341-1352. 
38. Wooles, A. J.; Mills, D. P.; Tuna, F.; McInnes, E. J. L.; Law, G. T. W.; Fuller, A. J.; Kremer, F.; Ridgway, M.; Lewis, W.; Gagliardi, L.; Vlaisavljevich, B.; Liddle, S. T., Uranium(III)-carbon multiple bonding supported by arene delta-bonding in mixed-valence hexauranium nanometre-scale rings. Nat. Commun. 2018, 9, 2097.

39. Patel, D.; Tuna, F.; McInnes, E. J. L.; McMaster, J.; Lewis, W.; Blake, A. J.; Liddle, S. T., A triamidouranium(V) inverse-sandwich $10 \pi$-toluene tetraanion arene complex. Dalton Trans. 2013, 42, 5224-5227.

40. Camp, C.; Mougel, V.; Pécaut, J.; Maron, L.; Mazzanti, M., Cation-Mediated Conversion of the State of Charge in Uranium Arene Inverted-Sandwich Complexes. Chem. Eur. J. 2013, 19, 17528-17540.

41. Yu, C.; Liang, J. F.; Deng, C.; Lefevre, G.; Cantat, T.; Diaconescu, P. L.; Huang, W. L., Arene-Bridged Dithorium Complexes: Inverse Sandwiches Supported by a delta Bonding Interaction. J. Am. Chem. Soc. 2020, $142,21292-21297$.

42. Evans, W. J.; Kozimor, S. A.; Ziller, J. W.; Kaltsoyannis, N., Structure, reactivity, and density functional theory analysis of the six-electron reductant, $\left[\left(\mathrm{C}_{5} \mathrm{Me}_{5}\right)_{2} \mathrm{U}\right]_{2}\left(\mu-\eta^{6}: \eta^{6}-\mathrm{C}_{6} \mathrm{H}_{6}\right)$, synthesized via a new mode of $\left(\mathrm{C}_{5} \mathrm{Me}_{5}\right)_{3} \mathrm{M}$ reactivity. J. Am. Chem. Soc. 2004, 126, 14533-14547.

43. Arnold, P. L.; Mansell, S. M.; Maron, L.; McKay, D., Spontaneous reduction and C-H borylation of arenes mediated by uranium(III) disproportionation. Nat. Chem. 2012, 4, 668-674.

44. Arnold, P. L.; Halliday, C. J. V.; Puig-Urrea, L.; Nichol, G. S., Instantaneous and Phosphine-Catalyzed Arene Binding and Reduction by U(III) Complexes. Inorg. Chem. 2021, 60, 4162-4170.

45. La Pierre, H. S.; Scheurer, A.; Heinemann, F. W.; Hieringer, W.; Meyer, K., Synthesis and Characterization of a Uranium(II) Monoarene Complex Supported by $\delta$ Backbonding. Angew. Chem. Int. Ed. 2014, 53, 7158-7162.

46. Billow, B. S.; Livesay, B. N.; Mokhtarzadeh, C. C.; McCracken, J.; Shores, M. P.; Boncella, J. M.; Odom, A. L., Synthesis and Characterization of a Neutral U(II) Arene Sandwich Complex. J. Am. Chem. Soc. 2018, 140, 17369-17373.

47. Tian, J. N.; Zheng, M.; Li, L.; Schreckenbach, G.; Guo, Y. R.; Pan, Q. J., Theoretical investigation of U(I) arene complexes: is the elusive monovalent oxidation state accessible? New J. Chem. 2019, 43, 1469-1477.

48. Bart, S. C.; Heinemann, F. W.; Anthon, C.; Hauser, C.; Meyer, K., A New Tripodal Ligand System with Steric and Electronic Modularity for Uranium Coordination Chemistry. Inorg. Chem. 2009, 48, 9419-9426.

49. Halter, D. P.; La Pierre, H. S.; Heinemann, F. W.; Meyer, K., Uranium(IV) Halide (F-, Cl-, Br-, and I-) Monoarene Complexes. Inorg. Chem. 2014, 53, 8418-8424.

50. La Pierre, H. S.; Kameo, H.; Halter, D. P.; Heinemann, F. W.; Meyer, K., Coordination and Redox Isomerization in the Reduction of a Uranium(III) Monoarene Complex. Angew. Chem. Int. Edit. 2014, 53, 7154-7157.

51. Franke, S. M.; Tran, B. L.; Heinemann, F. W.; Hieringer, W.; Mindiola, D. J.; Meyer, K., Uranium(III) Complexes with Bulky Aryloxide Ligands Featuring Metal-Arene Interactions and Their Reactivity Toward Nitrous Oxide. Inorg. Chem. 2013, 52, 10552-10558.

52. Arnold, P. L.; Farnaby, J. H.; White, R. C.; Kaltsoyannis, N.; Gardiner, M. G.; Love, J. B., Switchable picoordination and $\mathrm{C}-\mathrm{H}$ metallation in small-cavity macrocyclic uranium and thorium complexes. Chem. Sci. 2014, $5,756-765$. 
53. Arnold, P. L.; Farnaby, J. H.; Gardiner, M. G.; Love, J. B., Uranium(III) Coordination Chemistry and Oxidation in a Flexible Small-Cavity Macrocycle. Organometallics 2015, 34, 2114-2117.

54. Suvova, M.; O’Brien, K. T. P.; Farnaby, J. H.; Love, J. B.; Kaltsoyannis, N.; Arnold, P. L., Thorium(IV) and Uranium(IV) trans-Calix[2]benzene[2]pyrrolide Alkyl and Alkynyl Complexes: Synthesis, Reactivity, and Electronic Structure. Organometallics 2017, 36, 4669-4681.

55. Fortier, S.; Aguilar-Calderon, J. R.; Vlaisavljevich, B.; Metta-Magana, A. J.; Goos, A. G.; Botez, C. E., An N-Tethered Uranium(III) Arene Complex and the Synthesis of an Unsupported U-Fe Bond. Organometallics 2017, $36,4591-4599$.

56. Yadav, M.; Metta-Magana, A. J.; Fortier, S., Intra- and intermolecular interception of a photochemically generated terminal uranium nitride. Chem. Sci. 2020, 11, 2381-2387.

57. Inman, C. J.; Frey, A. S. P.; Kilpatrick, A. F. R.; Cloke, F. G. N.; Roe, S. M., Carbon Dioxide Activation by a Uranium(III) Complex Derived from a Chelating Bis(aryloxide) Ligand. Organometallics 2017, 36, 45394545.

58. Arunachalampillai, A.; Crewdson, P.; Korobkov, I.; Gambarotta, S., Ring Opening and C-O and C-N Bond Cleavage by Transient Reduced Thorium Species. Organometallics 2006, 25, 3856-3866.

59. Korobkov, I.; Gorelsky, S.; Gambarotta, S., Reduced Uranium Complexes: Synthetic and DFT Study of the Role of pi Ligation in the Stabilization of Uranium Species in a Formal Low-Valent State. J. Am. Chem. Soc. 2009, 131, 10406-10420.

60. Gunko, Y. K.; Hitchcock, P. B.; Lappert, M. F., Activation of a C-O Bond by Reaction of a Tris(Cyclopentadienyl)Lanthanide Complex with an Alkali-Metal in Dimethoxyethane (DME) - Crystal-Structures of [Nd $\left(\eta^{5}-\right.$ $\left.\left.\mathrm{C}_{5} \mathrm{H}_{3}\left(\mathrm{SiMe}_{3}\right)_{2}-1,3\right)_{2}(\mu-\mathrm{OMe})_{2} \mathrm{Li}(\mathrm{DME})\right]$ and $\left[\left(\mathrm{Ce}\left(\eta^{5}-\mathrm{C}_{5} \mathrm{H}_{3}{ }^{t} \mathrm{Bu}_{2}-1,3\right)_{2}(\mu-\mathrm{OMe})\right)_{2}\right]$. J. Organomet. Chem. 1995, 499, 213-219.

61. Castillo, M.; Metta-Magaña, A. J.; Fortier, S., Isolation of gravimetrically quantifiable alkali metal arenides using 18-crown-6. New J. Chem. 2016, 40, 1923-1926.

62. Seaburg, J. K.; Fischer, P. J.; Young, J., Victor G.; Ellis, J. E., First Isolation and Structural Characterization of Bis(Anthracene)Metal Complexes: [Ti $\left.\left(\eta^{6}-\mathrm{C}_{14} \mathrm{H}_{10}\right)\left(\eta^{4}-\mathrm{C}_{14} \mathrm{H}_{10}\right)\left(\eta^{2}-\mathrm{dmpe}\right)\right]$ and $\left[\mathrm{Ti}\left(\eta^{4}-\mathrm{C}_{14} \mathrm{H}_{10}\right)\left(\eta^{2}-\mathrm{C}_{14} \mathrm{H}_{10}\right)\left(\eta^{5}-\right.\right.$ $\left.\left.\mathrm{C}_{5} \mathrm{Me}_{5}\right)\right]^{-}$. Angew. Chem. Int. Ed. 1998, 37, 155-158.

63. Bochkarev, M. N.; Fedushkin, I. L.; Fagin, A. A.; Schumann, H.; Demtschuk, J., Triple-decker naphthalene complex of thulium(III); synthesis and molecular structure of $\left[\{\mathrm{Tm}(\mathrm{DME})\}_{2}\left(\eta^{2}-\mathrm{C}_{10} \mathrm{H}_{8}\right)_{2}\left(\mu_{2}-\eta^{4}: \eta^{4}-\mathrm{C}_{10} \mathrm{H}_{8}\right)\right]$. Chem. Commun. 1997, 1783-1784.

64. Labrum, N. S.; Losovyj, Y.; Caulton, K. G., A new access route to dimetal sandwich complexes, including a radical anion. Chem. Commun. 2018, 54, 12397-12399.

65. Tsoureas, N.; Mansikkamaki, A.; Layfield, R. A., Uranium(IV) cyclobutadienyl sandwich compounds: synthesis, structure and chemical bonding. Chem. Commun. 2020, 56, 944-947.

66. Shannon, R. D., Revised Effective Ionic-Radii and Systematic Studies of Interatomic Distances in Halides and Chalcogenides. Acta Crystallogr. A 1976, 32, 751-767.

67. Falceto, A.; Casanova, D.; Alemany, P.; Alvarez, S., Distortions of $\pi$-Coordinated Arenes with Anionic Character. Chem. Eur. J. 2014, 20, 14674-14689. 
68. Engelhardt, L. M.; Harvey, S.; Raston, C. L.; White, A. H., Organo-Magnesium Reagents - the CrystalStructures of $\left[\mathrm{Mg}(\right.$ Anthracene $\left.)(\mathrm{THF})_{3}\right]$ and $\left[\mathrm{Mg}(\right.$ Triphenylmethyl $\left.) \mathrm{Br}\left(\mathrm{OEt}_{2}\right)_{2}\right]$. J. Organomet. Chem. 1988, 341, 3951.

69. Bogdanovic, B., Magnesium anthracene systems and their application in synthesis and catalysis. Acc. Chem. Res. 1988, 21, 261-267.

70. Roitershtein, D. M.; Ellern, A. M.; Antipin, M. Y.; Rybakova, L. F.; Struchkov, Y. T.; Petrov, E. S., The First Structurally Characterized Organolanthanoid Compound with an Anthracene Dianion Ligand. Synthesis and Structure (at $143 \mathrm{~K}$ ) of $\eta^{5}-\left(\mathrm{C}_{5} \mathrm{H}_{5}\right) \mathrm{Lu}\left(\mathrm{C}_{14} \mathrm{H}_{10}{ }^{2-}\right) \cdot 2 \mathrm{THF}(\mathrm{THF}=$ tetrahydrofuran). Mendeleev Commun. 1992, 2, 118120.

71. Fedushkin, I. L.; Bochkarev, M. N.; Dechert, S.; Schumann, H., A chemical definition of the effective reducing power of thulium(II) diiodide by its reactions with cyclic unsaturated hydrocarbons. Chem. Eur. J. 2001, 7, 3558-3563.

72. Velian, A.; Transue, W. J.; Cummins, C. C., Synthesis, Characterization, and Thermolysis of Dibenzo-7dimethylgermanorbornadiene. Organometallics 2015, 34, 4644-4646.

73. Brennessel, W. W.; Ellis, J. E.; Roush, S. N.; Strandberg, B. R.; Woisetschlager, O. E.; Young, V. G., Tris(1-4- $\eta^{4}$-anthracene)niobate(1-), the first polyaromatic hydrocarbon complex of niobium. Chem. Commun. 2002, 2356-2357.

74. Lusi, M.; Vitorica-Yrezabal, I. J.; Zaworotko, M. J., Expanding the Scope of Molecular Mixed Crystals Enabled by Three Component Solid Solutions. Cryst. Growth Des. 2015, 15, 4098-4103.

75. Fortenberry, R. C.; Novak, C. M.; Lee, T. J.; Bera, P. P.; Rice, J. E., Identifying Molecular Structural Aromaticity for Hydrocarbon Classification. ACS Omega 2018, 3, 16035-16039.

76. Minsky, A.; Meyer, A. Y.; Poupko, R.; Rabinovitz, M., Paramagnetism and Antiaromaticity - Singlet Triplet Equilibrium in Doubly Charged Benzenoid Polycyclic Systems. J. Am. Chem. Soc. 1983, 105, 2164-2172.

77. Kindra, D. R.; Evans, W. J., Magnetic Susceptibility of Uranium Complexes. Chem. Rev. 2014, 114, 88658882.

78. Fortier, S.; Melot, B. C.; Wu, G.; Hayton, T. W., Homoleptic Uranium(IV) Alkyl Complexes: Synthesis and Characterization. J. Am. Chem. Soc. 2009, 131, 15512-15521.

79. Bes, R.; Rivenet, M.; Solari, P. L.; Kvashnina, K. O.; Scheinost, A. C.; Martin, P. M., Use of HERFDXANES at the U L-3- and M-4-Edges To Determine the Uranium Valence State on $\left[\mathrm{Ni}\left(\mathrm{H}_{2} \mathrm{O}\right)_{4}\right]_{3}\left[\mathrm{U}\left(\mathrm{OH}, \mathrm{H}_{2} \mathrm{O}\right)\left(\mathrm{UO}_{2}\right)_{8} \mathrm{O}-12(\mathrm{OH})_{3}\right]$. Inorg. Chem. 2016, 55, 4260-4270.

80. Kosog, B.; La Pierre, H. S.; Denecke, M. A.; Heinemann, F. W.; Meyer, K., Oxidation State Delineation via $\mathrm{U}_{\mathrm{III}}$-Edge XANES in a Series of Isostructural Uranium Coordination Complexes. Inorg. Chem. 2012, 51, 7940-7944.

81. Anderson, N. H.; Odoh, S. O.; Williams, U. J.; Lewis, A. J.; Wagner, G. L.; Pacheco, J. L.; Kozimor, S. A.; Gagliardi, L.; Schelter, E. J.; Bart, S. C., Investigation of the Electronic Ground States for a Reduced Pyridine(diimine) Uranium Series: Evidence for a Ligand Tetraanion Stabilized by a Uranium Dimer. J. Am. Chem. Soc. 2015, 137, 4690-4700. 
82. Kraft, S. J.; Williams, U. J.; Daly, S. R.; Schelter, E. J.; Kozimor, S. A.; Boland, K. S.; Kikkawa, J. M.; Forrest, W. P.; Christensen, C. N.; Schwarz, D. E.; Fanwick, P. E.; Clark, D. L.; Conradson, S. D.; Bart, S. C., Synthesis, Characterization, and Multielectron Reduction Chemistry of Uranium Supported by Redox-Active alpha-Diimine Ligands. Inorg. Chem. 2011, 50, 9838-9848.

83. Perdew, J. P.; Burke, K.; Ernzerhof, M., Generalized gradient approximation made simple. Phys. Rev. Lett. 1996, 77, 3865-3868.

84. Grimme, S.; Antony, J.; Ehrlich, S.; Krieg, H., A consistent and accurate ab initio parametrization of density functional dispersion correction (DFT-D) for the 94 elements H-Pu. J. Chem. Phys. 2010, 132, 154104.

85. Grimme, S.; Ehrlich, S.; Goerigk, L., Effect of the damping function in dispersion corrected density functional theory. J. Comput. Chem. 2011, 32, 1456-1465.

86. Weigend, F.; Häser, M.; Patzelt, H.; Ahlrichs, R., RI-MP2: optimized auxiliary basis sets and demonstration of efficiency. Chem. Phys. Lett. 1998, 294, 143-152.

87. Eichkorn, K.; Weigend, F.; Treutler, O.; Ahlrichs, R., Auxiliary basis sets for main row atoms and transition metals and their use to approximate Coulomb potentials. Theor. Chem. Acc. 1997, 97, 119-124.

88. Küchle, W.; Dolg, M.; Stoll, H.; Preuss, H., Energy-adjusted pseudopotentials for the actinides. Parameter sets and test calculations for thorium and thorium monoxide. J. Chem. Phys. 1994, 100, 7535-7542.

89. Cao, X.; Dolg, M.; Stoll, H., Valence basis sets for relativistic energy-consistent small-core actinide pseudopotentials. J. Chem. Phys. 2003, 118, 487-496.

90. TURBMOLE V7.3 2018, a development of the University of Karlsruhe and Forschungszentrum Karlsruhe GmBH, 1989-2007, TURBMOLE GmbH, since 2007; available from http://www.turbomole.com

91. G. te Velde, G.; Bickelhaupt, F. M.; Baerends, E. J.; Guerra, C. F.; Van Gisbergen, S. J. A.; Snijders, J. G.; Ziegler, T., Chemistry with ADF. J. Comput. Chem. 2001, 22, 931-967.

92. Mayer, I., Bond orders and valences from ab initio wave functions. Int. J. Quantum Chem. 1986, 29, 477483.

93. Huang, Q.-R.; Kingham, J. R.; Kaltsoyannis, N., The strength of actinide-element bonds from the quantum theory of atoms-in-molecules. Dalton Trans. 2015, 44, 2554-2566.

94. Andersson, K.; Malmqvist, P. A.; Roos, B. O., 2nd-Order Perturbation-Theory with a Complete Active Space Self-Consistent Field Reference Function. J. Chem. Phys. 1992, 96, 1218-1226.

95. Andersson, K.; Malmqvist, P. A.; Roos, B. O.; Sadlej, A. J.; Wolinski, K., 2nd-Order Perturbation-Theory with a CASSCF Reference Function. J. Phys. Chem. 1990, 94, 5483-5488.

96. Malmqvist, P. A.; Pierloot, K.; Shahi, A. R. M.; Cramer, C. J.; Gagliardi, L., The restricted active space followed by second-order perturbation theory method: Theory and application to the study of $\mathrm{CuO} 2$ and $\mathrm{Cu} 2 \mathrm{O} 2$ systems. J. Chem. Phys. 2008, 128.

97. Sauri, V.; Serrano-Andres, L.; Shahi, A. R. M.; Gagliardi, L.; Vancoillie, S.; Pierloot, K., Multiconfigurational Second-Order Perturbation Theory Restricted Active Space (RASPT2) Method for Electronic Excited States: A Benchmark Study. J. Chem. Theory Comput. 2011, 7, 153-168. 
98. Aquilante, F.; Autschbach, J.; Carlson, R. K.; Chibotaru, L. F.; Delcey, M. G.; De Vico, L.; Galvan, I. F.; Ferre, N.; Frutos, L. M.; Gagliardi, L.; Garavelli, M.; Giussani, A.; Hoyer, C. E.; Li Manni, G.; Lischka, H.; Ma, D. X.; Malmqvist, P. A.; Muller, T.; Nenov, A.; Olivucci, M.; Pedersen, T. B.; Peng, D. L.; Plasser, F.; Pritchard, B.; Reiher, M.; Rivalta, I.; Schapiro, I.; Segarra-Marti, J.; Stenrup, M.; Truhlar, D. G.; Ungur, L.; Valentini, A.; Vancoillie, S.; Veryazov, V.; Vysotskiy, V. P.; Weingart, O.; Zapata, F.; Lindh, R., Molcas 8: New capabilities for multiconfigurational quantum chemical calculations across the periodic table. J. Comput. Chem. 2016, 37, 506541. 